WHOI $-81-28$

\section{FIELD EVALUATION OF SEA DATA DIRECTIONAL WAVE GAGE (MODEL 635-9)}

by

D. G. Aubrey

WOODS HOLE OCEANOGRAPHIC INSTITUTION

Woods Hole, Massachusetts 02543

May 1981

TECHNICAL REPORT

Prepared for the Department of Commerce, NOAA

Office of Sea Grant under Grants NA79AA-D-00102

and NA80AA-D-00077 and for the U.S. Army Research Office, Contract DAAG29-81-K-0004.

Reproduction in whoie or in part is permitted for any purpose of the United States Goverment. This report should be cited as: Woods Hole Oceanog. Inst. Tech. Rept. WHOI-81-28.

Approved for Distribution:

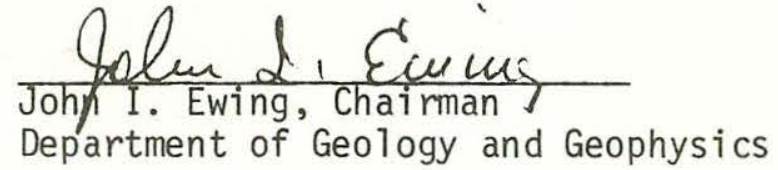




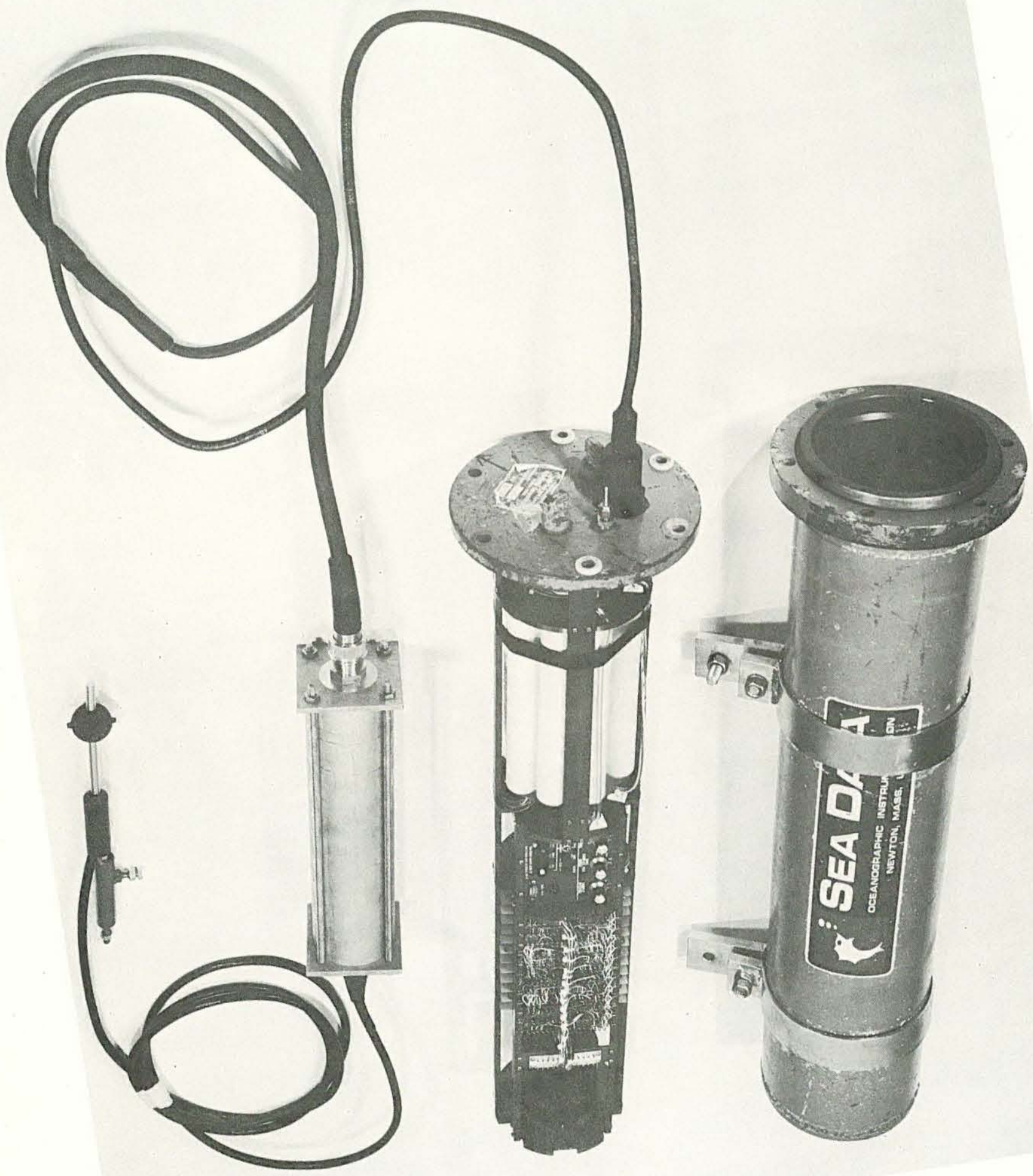




\author{
Field Evaluation of Sea Data Directional \\ Wave Gage (Mode 1 635-9) \\ by D. G. Aubrey
}

Abstract

A directional wave gage consisting of a two-axis electromagnetic current meter and a pressure sensor, developed by Sea Data Corporation, with modifications specified by the author, was successfully depioyed during the joint NOAA/U.S. Army Corps of Engineers Coastal Engineering Researcin Center's Atlantic Remote Sensing Land/Ocean Experiment (ARSLOE) during November, 1980. Data recovery rate was $100 \%$, and instrument function was verified through comparison with a four-element pressure sensor array at the same location, an X-band imaging radar, and with surface meteorological observations charting developing local wave fields. The instrument was proven to be a viable alternative for point measurements of directional wave fields and for estimating the first five fourier coefficients in a directional wave model. 
TABLE OF CONTENTS

PAGE

INTRODUCT ION 2

$\begin{array}{lr}\text { HARDWARE } & 8\end{array}$

INSTALLATION AND RETRIEVAL 9

$\begin{array}{ll}\text { SOFTWARE } & 14\end{array}$

$\begin{array}{ll}\text { RESULTS } & 17\end{array}$

$\begin{array}{ll}\text { CONCLUSIONS } & 21\end{array}$

$\begin{array}{ll}\text { ACKNOWLEDGEMENTS } & 30\end{array}$

REFERENCES

APPENDIX I 33

$\begin{array}{ll}\text { APPENDIX II } & 40\end{array}$

$\begin{array}{ll}\text { APPENDIX III } & 47\end{array}$ 


\section{Introduction}

A field evaluation of a compact, internally-recording directional wave gage was performed at Duck, N.C. (figure 1), in November, 1980, at the U.S. Army Corps of Engineer's Field Research Facility (FRF), as part of the Atlantic Remote Sensing Land/0cean Experiment (ARSLOE). The directional wave gage was built by Sea Data Corporation, of Newton, MA, with modifications specified by the author, for use in a Woods Hole Oceanographic Institution Sea Grant project evaluating tidal inlet dynamics at Nauset Inlet, Cape Cod, MA (Aubrey, 1979). Participation in ARSLOE was designed to evaluate the performance of the Sea Data system against that of other directional wave gages sampling simultaneously.

ARSLOE, jointly sponsored by the NOAA Ocean Waves Program and the U.S. Army's Coastal Engineering Research Center (CERC), was a field experiment designed to intercompare remote and in situ observations of the ocean surface wave field. Added to this was an effort to acquire synoptic observations of the physics of ocean wave generation, growth, and dissipation. Table 1 presents the various types of instrumentation deployed, responsible agencies, and dates of operation. The Sea Data system is 1isted as ARSLOE number 91.

A post-experiment workshop was held by ARSLOE at Virginia Beach, VA., from February 18-20, 1980, with the intent of coordinating comparisons between the various instrument platforms, and to develop working groups for investigating different elements of surface wave generation, propagation, and dissipation. 


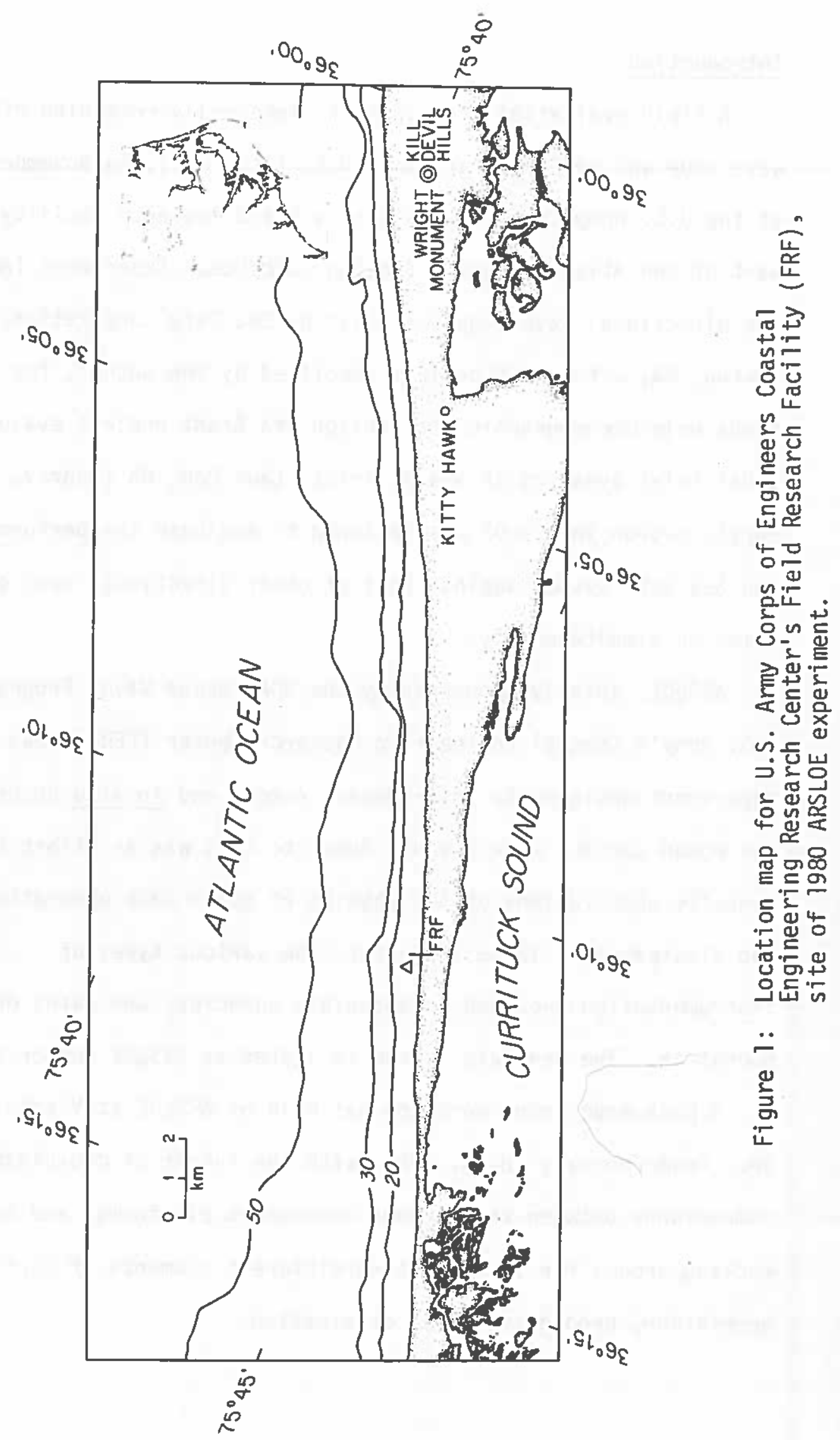


TABLE I

List of ARSLOE participants, sensor types, and location of sensors relaive to the Field Research Facility (FRF).

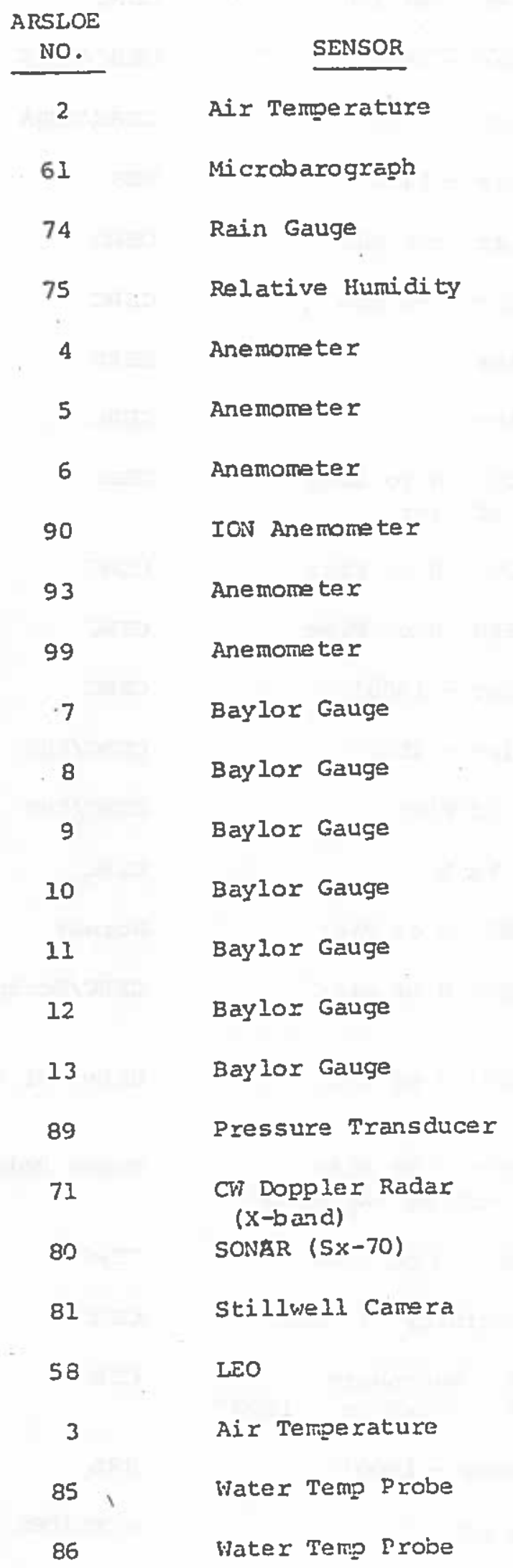

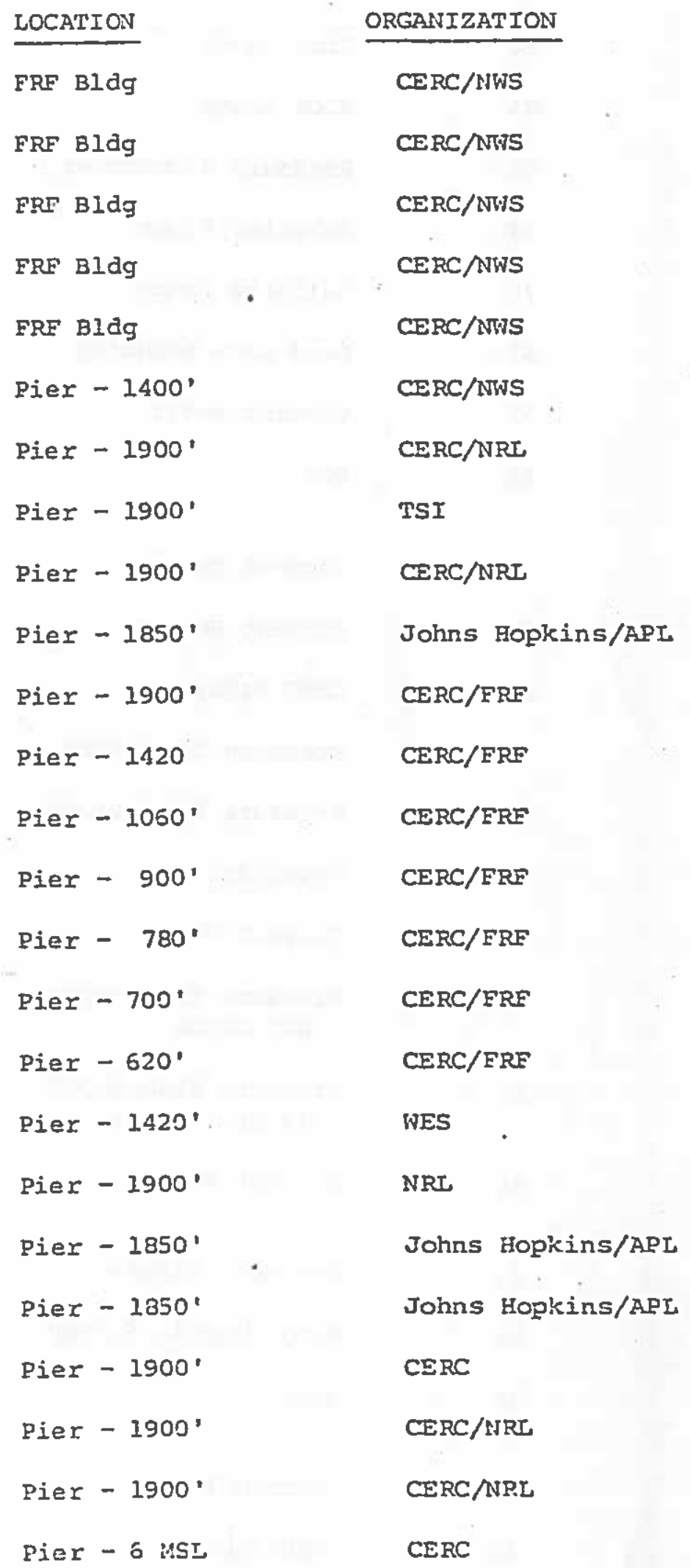


87

84

83

66

77

78

57

52

55

49

51

67

62

63

33

54

64

s
Water Temp Probe

Tide Gauge

Tide Gauge

Pressure Dransducer

Salinity Probe

Salinity Probe

Lead Line Sounding

Current Meter

Dye

Current Meter

Current Meter

CERC Radar

Pressure Transducer

Pressure Transducer

Waverider

Current Meter

Pressure Transducer SXY Gauge

Pressure Transducer

(3 pt. array)

Current Meter

Concrete Blocks

Hydrographic Survey

Rods

Current Meter

WADI BUOY
Pier -20 MSL

Pier - 1900'

Pier - 720'

Pier - 1420'

Pier -22 MSI

Pier -6 MSI.

Piex

Pier

$1000^{\circ} \mathrm{N}$ to $1000^{\prime}$ of Pier

$1000^{\prime} \mathrm{N}$ of Pier

$500^{\prime} N$ of Pier

Pier - $190^{\circ}$

Pier - 1900"

$\mathrm{N}$ of Pier

$I \mathrm{kmE}$

$800^{\prime} \mathrm{N}$ of Pier

$800^{\prime} \mathrm{N}$ of Pier

$800^{\prime} \mathrm{N}$ of Pier

$800^{\prime} \mathrm{N}$ of Pier top of SXY Gauge

Beyond of pier

Vicinity of Pier

A - Nearshore

B - Offshore - 1900'

Pier - 1900'

$3 \mathrm{~km}$
CERC

CERC/NOAA

CERC/NOAA

WES

CERC

CERC

CERC

CERC

CERC

CERC

CERC

CERC

CERC/FRF

CERC/EPF

CERC

Norway

CERC/Scripps

Univ. of Florida

Woods Hole

CERC

CERC

CERC

NRI.

NEPEIDES 


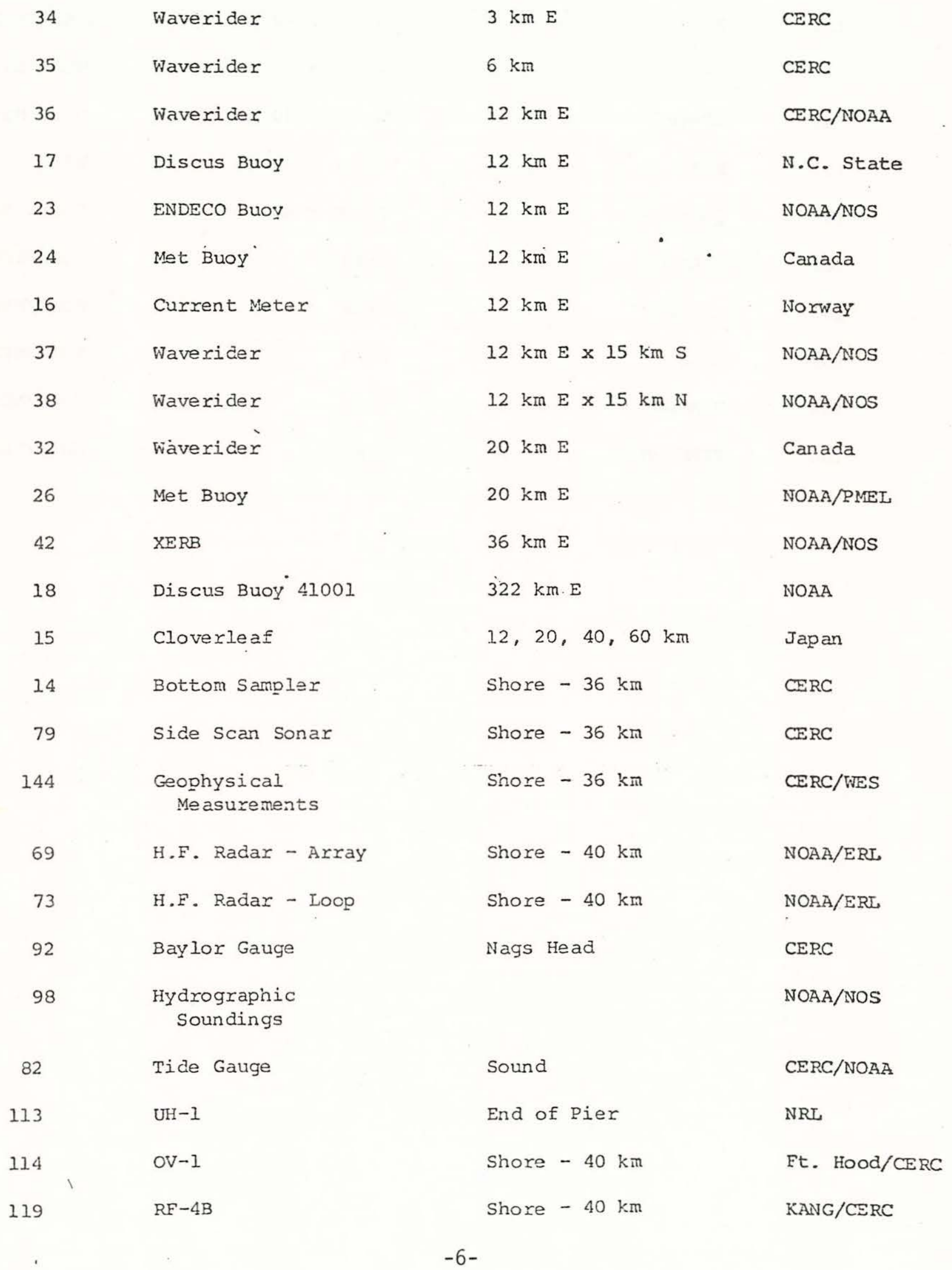




$\begin{array}{ll}121: & \mathrm{P}-3 \\ 127 & \mathrm{P}-3 \\ 139 & \mathrm{P}-3 \\ 131 \mathrm{~B} & \text { Queen Air } \\ 134 & \text { NOAA-6 } \\ 101 & \text { LANDSAT } \\ 103 & \text { GOES } \\ 102 & \text { NIMBUS-7 } \\ 106 & \text { TIROS }-\mathrm{N} \\ 100 & \end{array}$

$\begin{array}{ll}\text { Shore - } 40 \mathrm{~km} & \text { NASA/NRU } \\ \text { Shore - } 40 \mathrm{~km} & \text { NOAA/SAIL } \\ \text { Shore - } 40 \mathrm{~km} & \text { U.S. Marine Corps } \\ \text { Shore - } 40 \mathrm{~km} & \text { NRI } \\ \text { Shore - } 40 \mathrm{~km} & \text { Photo Science/ETL } \\ \text { Area } & \text { NOAA/NESS } \\ \text { Area } & \text { NOAA/NESS } \\ \text { Area } & \text { NOAA/NESS } \\ \text { Area } & \text { NOAA/NESS } \\ \text { Area } & \text { NOAA/NESS }\end{array}$


Hardware

The 635-9 directional wave gage consists of a Sea Data Corporation, cassette tape drive, with electronics for powering and sampling a pressure sensor and two-axis electromagnetic current meter. Power is supplied by a battery pack contained within an aluminum pressure case (coated with polyurethene paint). The pressure sensor is a Paroscientific, Inc., Digiquartz pressure transducer Model 245-A (0 to $45 \mathrm{psia}$ ), with a nominal precision of better than $0.01 \%$. The current meter is a Marsh McBirney, Inc., Model 512/0EM, two-axis electromagnetic sensor, with a sphere diameter of $3.81 \mathrm{~cm}$. In the configuration deployed at Duck, N.C., the pressure sensor was mounted in the cap of the pressure case, and the current meter was contained external to the pressure case, with a cable supplying power and transmitting data between the two. Sea Data has another configuration of the 635-9 in which the current meter probe is mounted directly on the end cap of the pressure case.

The Sea Data electronics provide a wide range of switch-selectable burst intervals, burst rates, and burst duration. In the ARSLOE experiment, burst rate was 1.0 seconds, burst interval was 6 nours, and burst duration was 2048 seconds. During each burst, samples of pressure and the two horizontal velocity components were taken. The time constant on the current meter was 0.25 seconds. Data was stored on a standard digital certified 450 foot $(137 \mathrm{~m})$ cassette tape, with a capacity of approximately 15 megabits of information, recorded on a four-track Sea Data cassette transport. This tape capacity corresponds to approximately forty-five days of data with the sampling 
parameters specified above. An internal clock provides elapsed time, which is also recorded on the digital cassette.

No compass was mounted in the pressure case during the ARSLOE experiment, although a Digicourse Model 225 gimbaled compass has been added since, to monitor any unexpected rotation of the rigid moorings to which the directional wave gage is attached.

A flooding problem with the electronics package of the Marsh-McBirney current meter, combined with a time constraint imposed by the ARSLOE experiment, precluded precalibration of the current meter by our lab before field installation. Immediately upon recovery from the field, however, a steady flow current meter calibration was run at WHOI in a tow tank (Figures 2 and 3). Over the range of velocities examined, the calibration curve is approximately linear. As demonstrated by Aubrey (1981), the 512 current meters must be calibrated in steady, oscillatory, and combined steady/oscillatory flows to obtain a true indication of their hydrodynamic performance. However, since even a careful laboratory flume test is not a complete description of the sphere's behavior in the field, we are using steady flow laboratory calibration as a standard for comparing current meter performance.

Installation and Retrieval

The 635-9 was deployed in Duck, N.C., on 31 October, 1980 (Figure 1). The internal clock was zeroed at 1900 hours eastern daylight time (EDT) on 29 0ctober, 1980, and cassette tape ARSLOE 10/80/2 was begun. Deployment was delayed two days (until approximately 1315 EDT on 31 0ctober, 1980) due to inclement weather 


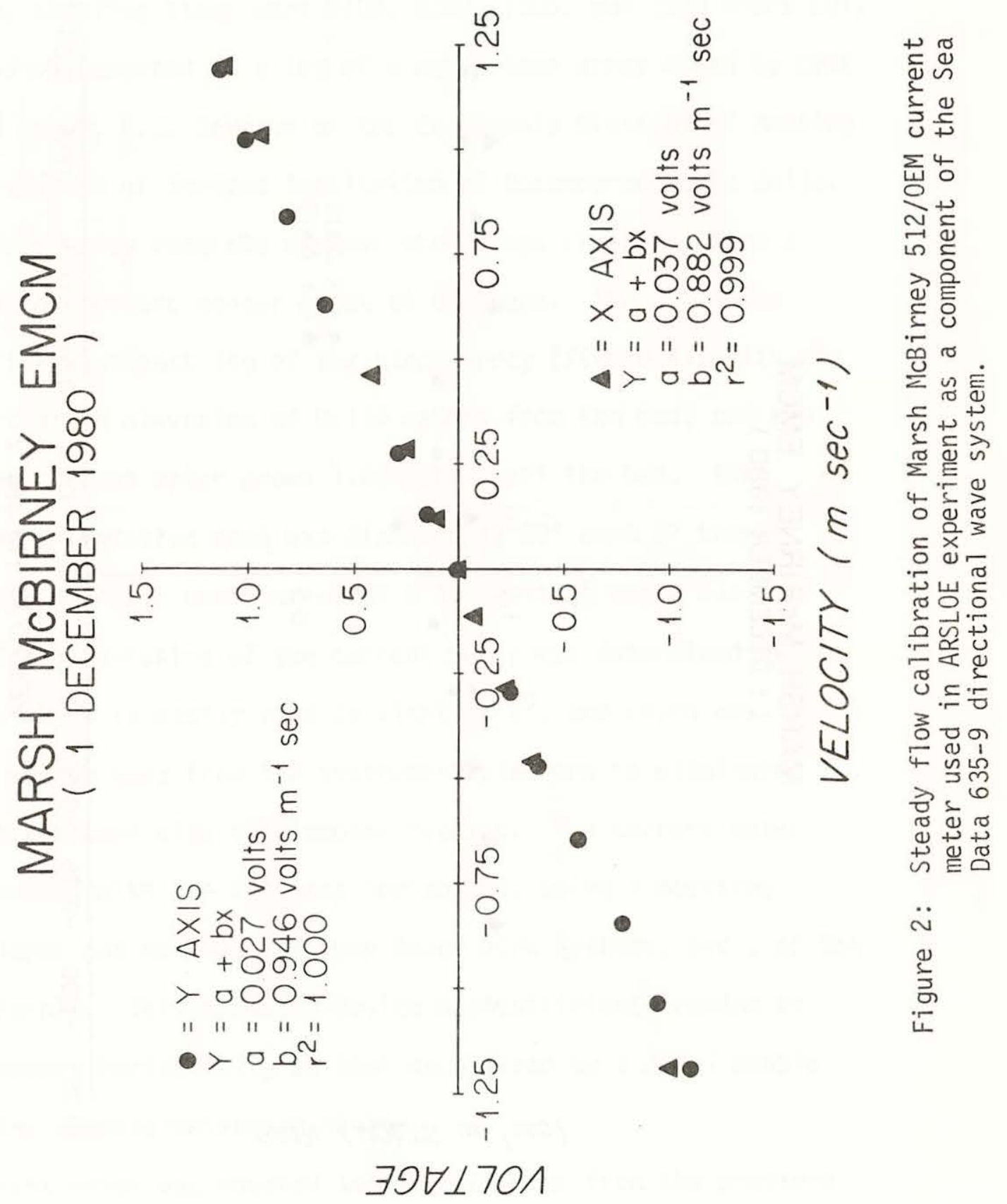




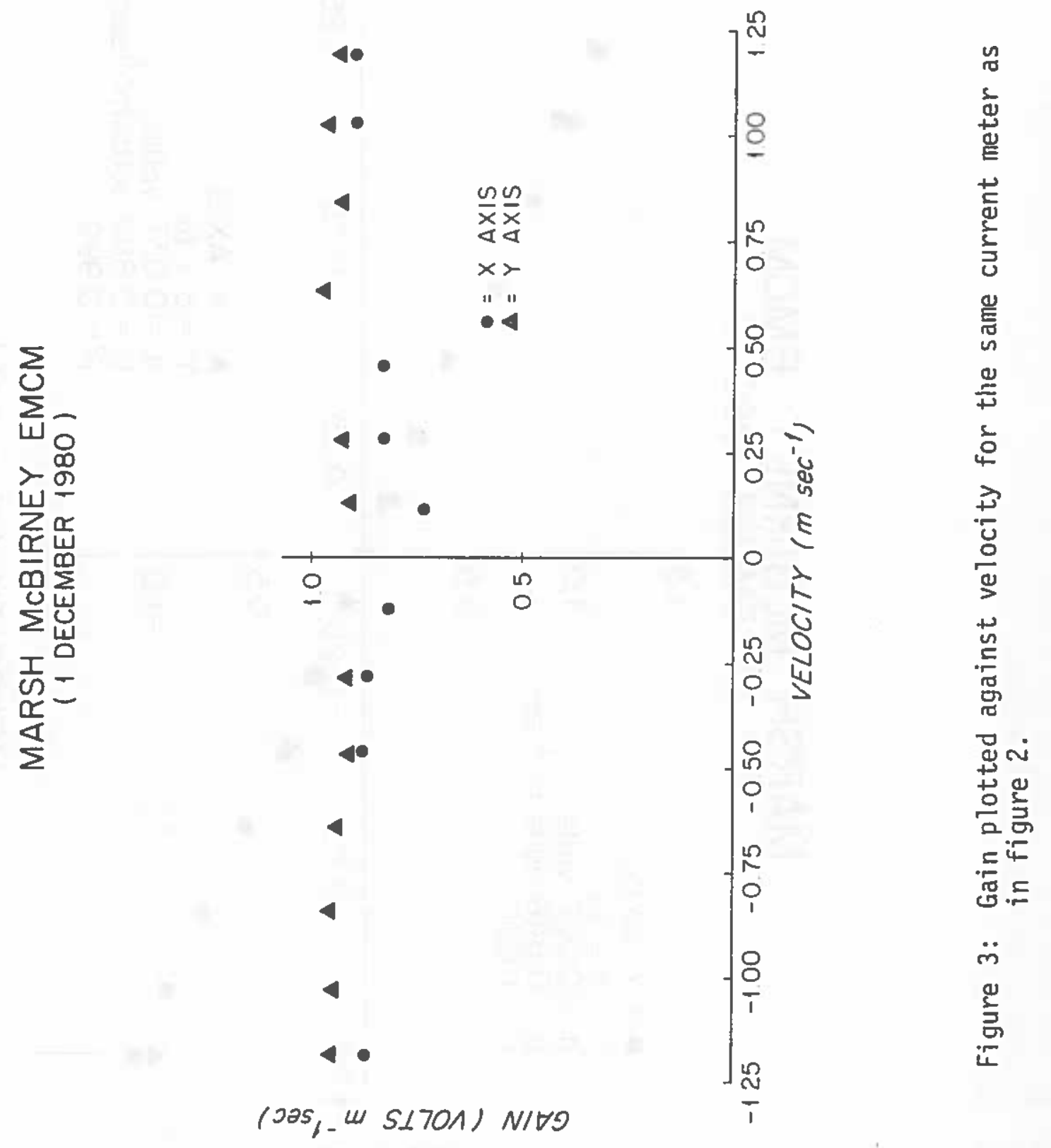


(an unforecasted local storm). Internal settings on the recorder were:

$\begin{array}{ll}\text { burst interval } & 6 \text { hours } \\ \text { burst duration } & 2048 \text { samples } \\ \text { burst rate } & 1 \text { samp le/second }\end{array}$

Consequent 1y, sampling times were $0100,0700,1300$, and 1900 hours EDT.

The 635-9 was mounted on a leg of a wave slope array owned by CERC and operated by Dr. R.J. Seymour of the California Division of Boating and Waterways (also of Scripps Institution of Oceanography, La Jolla, CA). The slope array consists of four steel legs radiating from a central core to pressure sensor cases at each end. The 635-9 was deployed on the southeast leg of the slope array (figure 4), with the pressure port at an elevation of 0.114 meters from the bed, and the center of the current meter probe 1.00 meters off the bed. The current meter orientation mark was directed $41^{\circ} 20^{\prime}$ east of true north (where a magnetic declination of $3^{0} 40^{\prime}$ west of north was assumed). The orientation of the current meter was determined by use of a compass which is easily read to within $\pm 2^{0}$, and which was mounted far enough away from the instrument platform to eliminate magnetic interference with the compass reading. The current meter probe was mounted with the two axes horizontal, using a mounting device developed and marketed by Deep Ocean work Systems, Inc., of San Pedro, California. This mounting device has sufficient freedom to orient the meters horizontally as best determined by a level bubble mounted on the compass/orienting device.

The current meter was mounted sufficiently far from the pressure housing and the slope array components to minimize flow interference, 


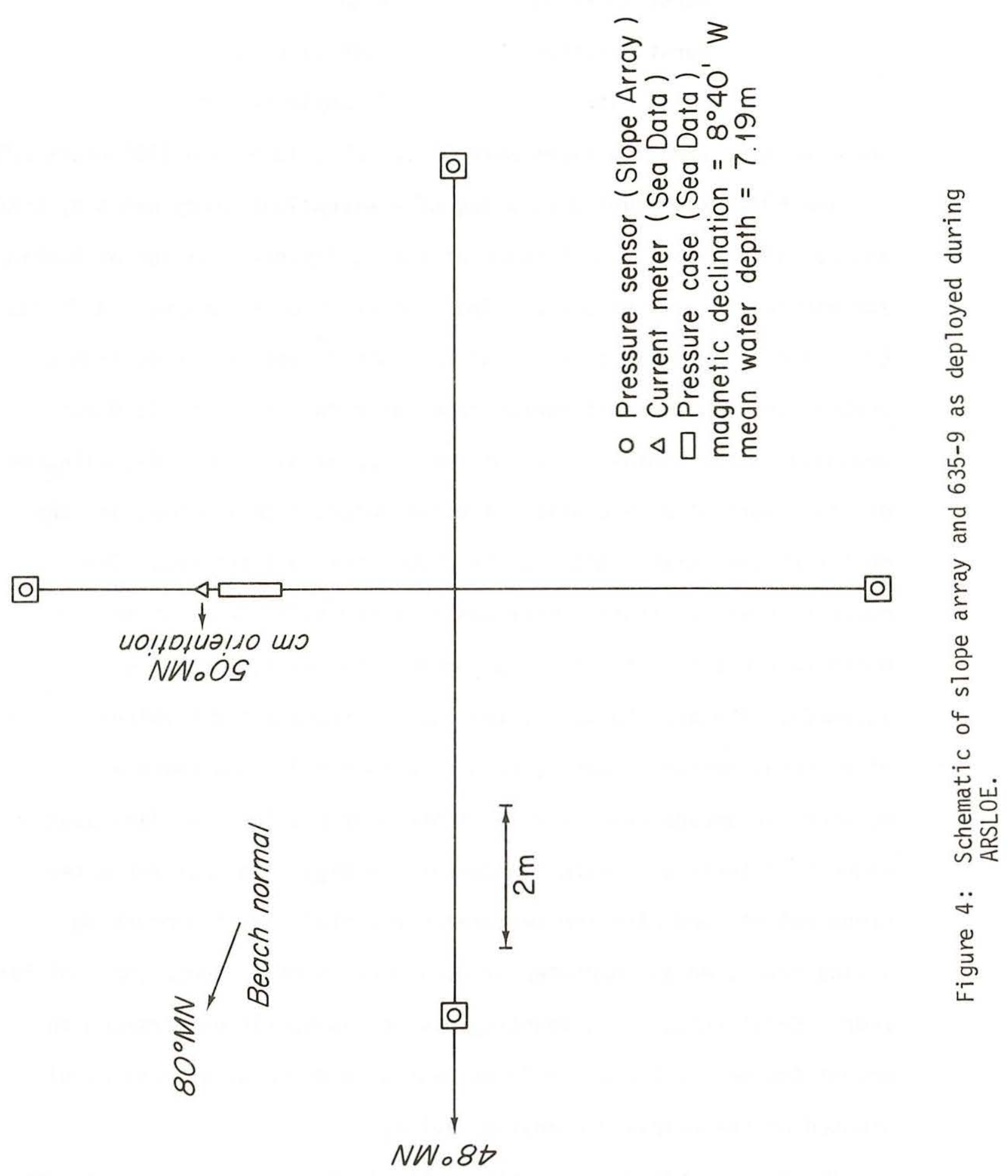


(and thus contaminated directional estimates). The two sensors were sufficiently close in the horizontal (approximately $0.5 \mathrm{~m}$ ) to eliminate phase differences between measured velocity and pressures, except for very short period waves which are effectively filtered by the water column.

The 635-9 directional wave gage was retrieved on 24 November 1980, during the period of largest waves encountered over the entire deployment. The orientation and tilt of the meter were verified during the retrieval, as best as possible considering the extreme wave conditions during the dive. No change in orientation of the gage appeared to have occurred during the deployment, and the current meter was free of biological contamination (algae, barnacles, mussels, etc.). The gage was out of the water by 1300 hours, EDT, on 24 November 1980. Retrieval of the gage coincided with the end of the ARSLOE experiment. At retrieval approximately half of the tape storage capacity remained, and the instrument was still functioning as designed. The instrument was removed under large wave conditions because of diver scheduling constraints.

In the following analyses, for comparison of wave direction to shore normal orientation, the shore normal is taken to be $72^{\circ}$ $\left(252^{\circ}\right)$ TN (figure 1). Mean water depth averaged over all burst intervals is 7.22 meters. All spectra are depth corrected. Software

The use of a two-axis electromagnetic current meter and a pressure sensor for determining wave direction is patterned after work performed by Longuet-Higgins, Cartwright, and Smith (1963), Cartwright 
(1963), and Nagata (1964). The directional wave spectrum is modeled as a fourier series truncated at five coefficients, with different coefficients for each frequency band:

$$
\begin{aligned}
S(f, \phi)=S(f) & {\left[a_{0}+2 / 3\left(a_{1} \cos \phi+b_{1} \sin \phi\right)\right.} \\
+ & \left.\frac{1}{6}\left(a_{2} \cos 2 \phi+b_{2} \sin 2 \phi\right)\right]
\end{aligned}
$$

$\hat{S}(f, \phi)$ is an estimate of the non-negative frequency-directional spectrum, $S(f)$ is the one-dimensional frequency spectrum, and the $a_{n}$ and $b_{n}$ terms are frequency-dependent fourier coefficients of the directional spectrum. Cross-spectra of the $u, v$, and $p$ terms yield:

$$
\begin{aligned}
& C_{p p}(\omega)=(\rho g)^{2} R^{2}(\omega) \int_{0}^{2 \pi} S(\omega, \phi) d \phi \\
& C_{u u}(\omega)=\frac{(g k)^{2}}{\omega^{2}} R^{2}(\omega) \int_{0}^{2 \pi} S(\omega, \phi) \cos ^{2} \phi d \phi \\
& C_{v v}(\omega)=\frac{(g k)^{2}}{\omega^{2}} R^{2}(\omega) \int_{0}^{2 \pi} S(\omega, \phi) \sin ^{2} \phi d \phi \\
& C_{p u}(\omega)=(\rho g) \frac{(g k)}{\omega} R^{2}(\omega) \int_{0}^{2 \pi} S(\omega, \phi) \cos \phi d \phi \\
& C_{p v}(\omega)=(\rho g) \frac{(g k)}{\omega} R^{2}(\omega) S_{0}^{2 \pi} S(\omega, \phi) \sin \phi d \phi \\
& C_{u v}(\omega)=\frac{(g k)^{2}}{2} R^{2}(\omega) \int_{0}^{2 \pi} S(\omega, \phi) \sin \phi \cos \phi d \phi
\end{aligned}
$$

where

$$
R(\omega)=\frac{\cosh k(z+h)}{\cosh k h}
$$


The relationships between the pressure and two horizontal velocity signals, and their auto- and cross-spectra, directly yield estimates of the fourier coefficients:

$$
\begin{aligned}
& a_{0}=\frac{1}{\pi} \frac{C_{p p}(\omega)}{(\rho g)^{2} R^{2}(\omega)}=\frac{1}{\pi} \frac{C_{u u}(\omega)+C_{v v}(\omega)}{G^{2}(\omega)} R^{2}(\omega) \\
& a_{1}=\frac{1}{\pi} \frac{C_{p u}(\omega)}{(\rho g) G(\omega) R^{2}(\omega)} \\
& b_{1}=\frac{1}{\pi} \quad \frac{C_{p v}(\omega)}{(\rho g) G(\omega) R^{2}(\omega)} \\
& a_{2}=\frac{1}{\pi} \frac{C_{u u}(\omega)-C_{v v}(\omega)}{G^{2}(\omega) R^{2}(\omega)} \\
& b_{2}=\frac{2}{\pi} \frac{C_{u v}(\omega)}{R^{2}(\omega) G^{2}(\omega)} \\
& G(\omega)=\frac{g k}{\omega}
\end{aligned}
$$

where $C_{\text {st }}$ represents the cross-spectrum between quantities $s$ and $t$ (auto-spectrum if $s=t$ ), $p$ is the pressure, $u$ and $v$ are the horizontal velocities, $h$ is the water depth, $d$ is the distance above the bed (with a subscript indicating either pressure or velocity), $z$ is the vertical coordinate positive upwards from the bed, $g$ is the acceleration of gravity, $\omega$ is the wave frequency (equal to 2 times $\pi$ divided by the wave period, $T$ ), $k$ is the wave number (equal to 2 times $\pi$ divided by the wave length, L). The cross spectra have zero quad spectra.

$\omega$ and $k$ are related by the formula:

$$
\omega^{2}=g k \tanh (k h)
$$

As demonstrated above, the pressure signal is necessary only to indicate local mean depth during the sample interval, since the sea 
surface fluctuations can be deduced alternatively by the two horizontal velocity components (generally at the expense of an increased noise level). The directional spectrum determined by this method is necessarily broad, given its representation by a truncated fourier series. It is convenient to define several measures of the directional spectrum:

$$
\begin{aligned}
& \text { Mean direction: } \bar{\phi}=\tan ^{-1}\left(b_{1} / a_{1}\right) \\
& \text { directional spread: } \overline{(\phi-\bar{\phi})^{2}}=2-2\left(a_{1}^{2}+b_{1}^{2}\right)^{1 / 2} / a_{0}
\end{aligned}
$$

Other estimates of directional spread are possible (see Longuet-Higgins et a1., 1963; Mardia, 1972).

Analysis of the directional properties of the observed waves was performed using the above equations. Spectral estimates were formed with record lengths of 2048 seconds (34.1 min), with 16 ensemble averages, yielding a record length of 128 seconds, and frequency resolution of 0.0078125 hertz. The resultant spectral estimates have 32 degrees of freedom. Al1 spectra are depth corrected.

Results

A modified form of the results of the analysis of the Duck, N.C., field data is presented in Appendix I. The compilation consists of date and run number $(1=0100,2=0700,3=1300$, and $4=1900$ EDT $)$, peak frequency, peak period, a qualitative estimate of bandwidth, total energy of the wave field in $\mathrm{cm}^{2}$ (defined as the variance of the sea surface elevation, $\left\langle n^{2}>\right.$ ), the energy in the peak period (qualitatively defined to indicate relative importance of different 
peaks in frequency), mean direction at modal frequency (in degrees, TN, direction towards whicn waves were propagating), and directional spread (in degrees), where a low spread indicates a narrower directional band. The data for the entire experiment were processed, with a $100 \%$ data recovery. Signal quality was uniformly good, with few outliers (glitches) or nigh frequency contamination. Before processing, all signals were demeaned and detrended (using a linear fit), so low frequency energy contamination is minimal, as expected in this nearsiore situation. Tabulated value of $<n^{2}>$ were calculated both from the velocity data and pressure signal. The close fit between the two calculations of $\left\langle n^{2}\right\rangle$ gives us more confidence in the use of the current meter for month-long deployments.

Appendix II presents frequency spectra derived from the slope array, in which the 635-9 was embedded. Data were provided by the Coastal Waves Network under the direction of Dr. R.J. Seymour. The latter data is band-averaged in a non-linear fashion (number of bands merged varies with frequency), so it is not possible to give a single equivalent number of degrees of freedom. Record length for these data is 1027 seconds (half the length of the 635-9 records discussed here). An intercomparison of the energy levels between the two wave sensing platforms has been performed (figure 5), showing remarkable correspondence between energy levels, considering the comparison was performed by calculating energies from the norizontal velocities for the 635-9. Since a current meter is often noisier than a pressure sensor (based on previous experience), velocity agreement indicates the current meter worked we11. As expected, comparison between the 


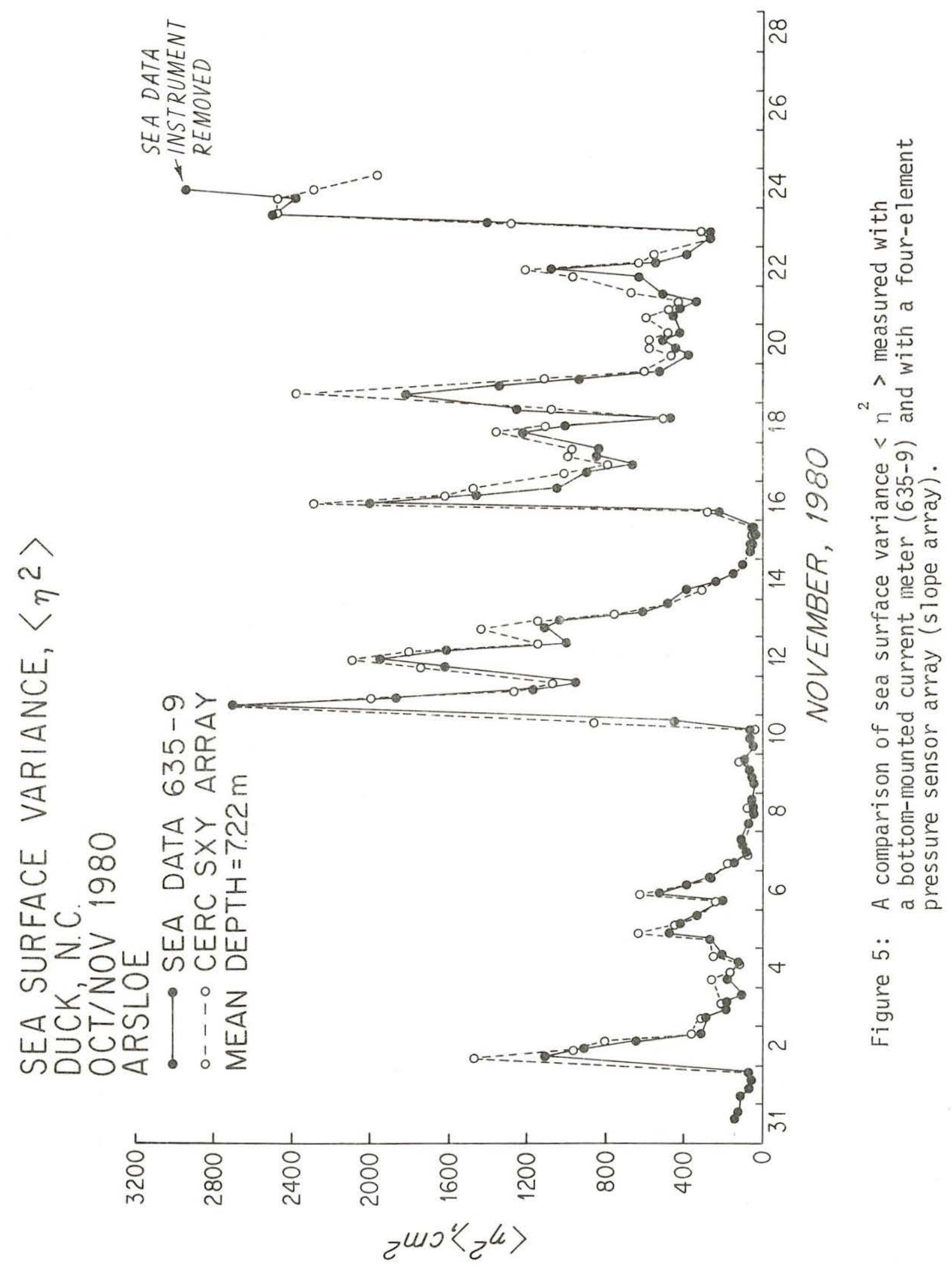


635-9 pressure sensor and slope array results was even better than that with the current meter. In order to intercompare results from Appendices I and II, the following relationships must be applied:

$$
\left\langle n^{2}>=\frac{1}{8} H_{r m s}{ }^{2}=\frac{1}{2} A_{r m s}{ }^{2}=\frac{1}{16} H_{1 / 3}{ }^{2}\right.
$$

Directional wave estimates from the slope array were recently provided to us (Appendix 3). Comparison between directions at modal frequencies can be made using Appendices 1 and 3. The two directional estimates agree well (no r.m.s. errors have been calculated yet), but comprehensive comparison is not yet possible because of differences in analysis. The slope array mean directions may not correspond exactly with the 635-9 directions, and the nonlinear (in frequency) band averaging of the slope array may yield different results than our ensemble averages. A more quantitative comparison should be possible at a later date.

In addition, X-band surface imaging radar provided by CERC (see Mattie and Harris, 1979) was examined at the ARSLOE workshop in February, 1981, to intercompare with the results of the 635-9 measurements. A comparison of radar imagery surrounding the 635-9, over a variety of different wave conditions, qualitatively verified the directional estimates derived using the 635-9. Primary and secondary wave trains during several large and small wave events were jointly identified on the two types of observations (both of which have their particular weaknesses, without doubt). This qualitative agreement lends credence to the results of the in situ point-array measurement with the 635-9. 
Wind data from the area (provided by the National Water Research Institute, Canada) lends further support to the 635-9 directional estimates (figure 6). By following the direction and magnitude of local winds, the development of local surface wind waves can be inferred. The growth and development of local wind waves, and their mean direction, agree wel1 with directional estimates from the 635-9.

Examples of frequency spectra from several different periods are presented in figures 7 through 13, corresponding to periods with varying wave conditions. The frequency spectra, which have been band-limited to frequencies less than $0.25 \mathrm{~Hz}$ (due to the asymptotic nature of the frequency dependent depth correction to bottom pressure), clearly illustrate differences between unimodal swell and locally-generated wind wave fields.

Conclusions

The Sea Data Corporation model 635-9 directional wave gage performed well in a field intercomparison experiment at CERC's Field Research Facility at Duck, N.C. Over the period of its deployment from 31 October 1980 through 24 November, 1980, the gage sampled four times daily for 2048 seconds per burst, with a 100\% data recovery. Frequency spectral estimates agree closely with those taken using a pressure sensor array within which the 635-9 was embedded. Directional estimates derived from the 635-9 qualitatively agree with slope array measurements, surface imaging radar and wind stress records taken at a nearby station. No quantitative directional comparisons are available with the radar and wind information (they have not yet been quantitatively analyzed) or with the slope array (because of differences in bandwidtin and differences in analysis). $-21-$ 


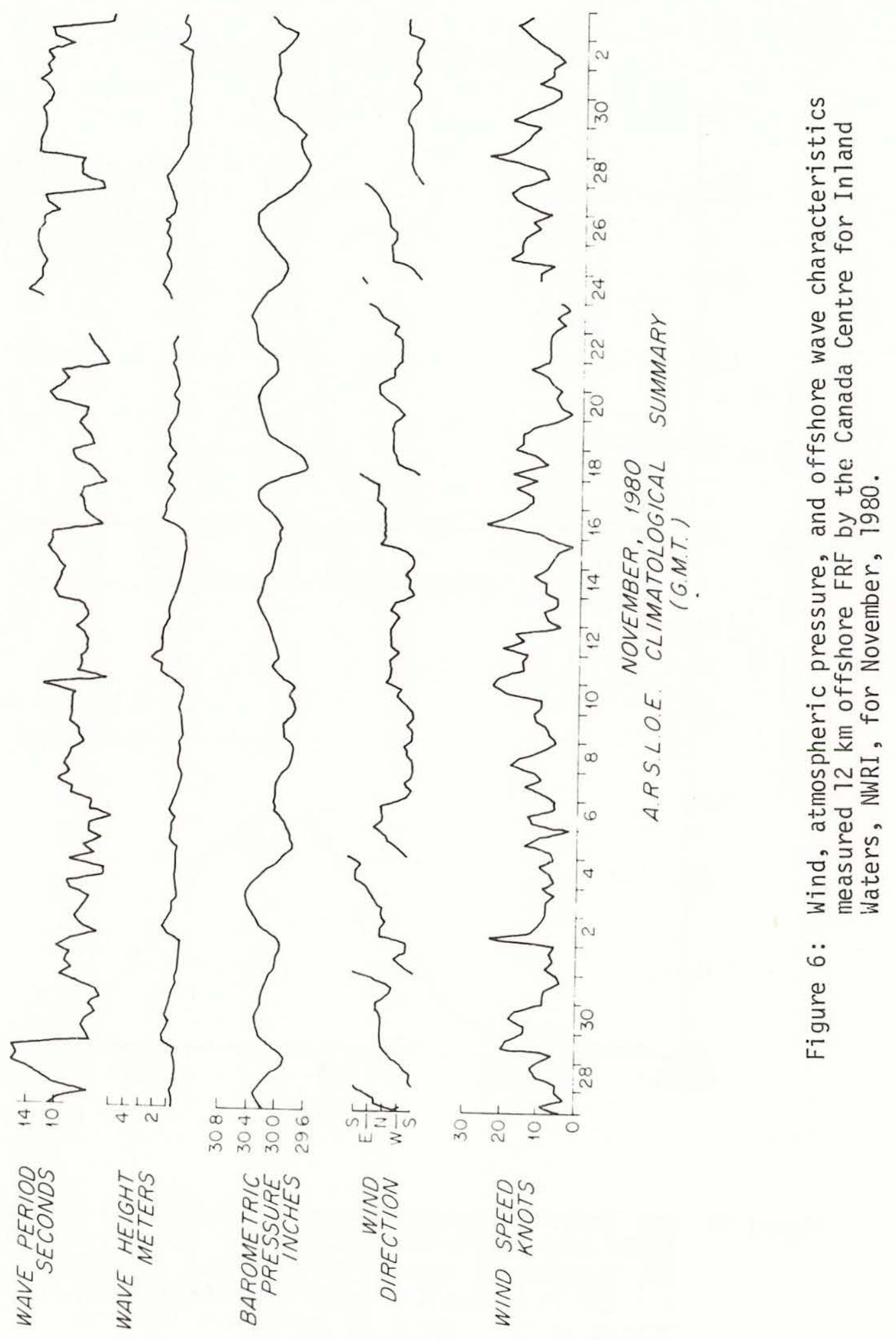


SEA SURFACE SPECTRUM

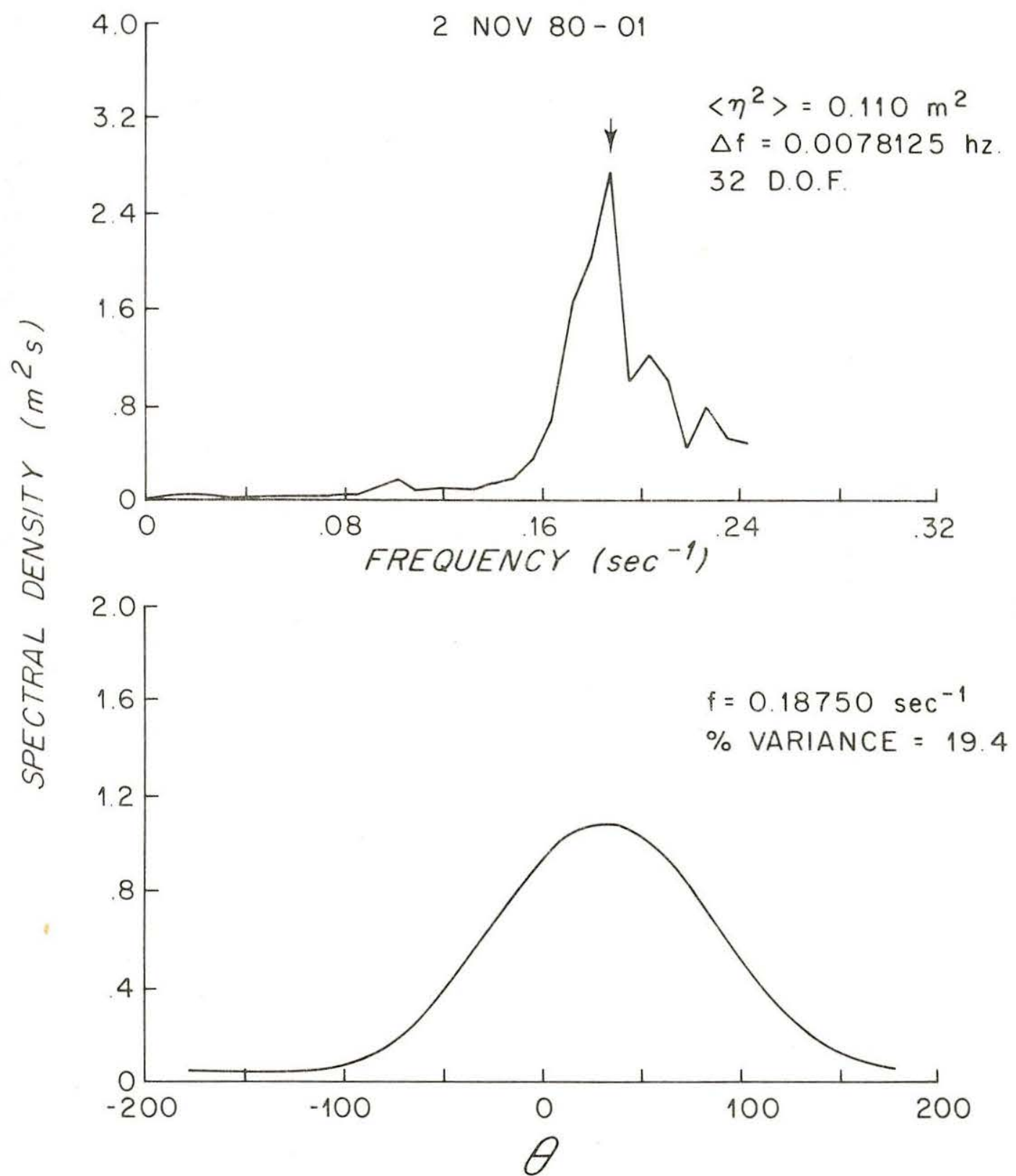

Figure 7: (a) Depth-corrected frequency spectrum for 2 November 1980 (0100 hrs), calculated from u, v. Peak is near 5 seconds. (b) Directional specrum at frequency $=0.1875 \mathrm{hz}$ $\phi=320 \mathrm{TN}$ (direction waves are coming from), and angular 'spread is 170 . Units of energy are relative. 

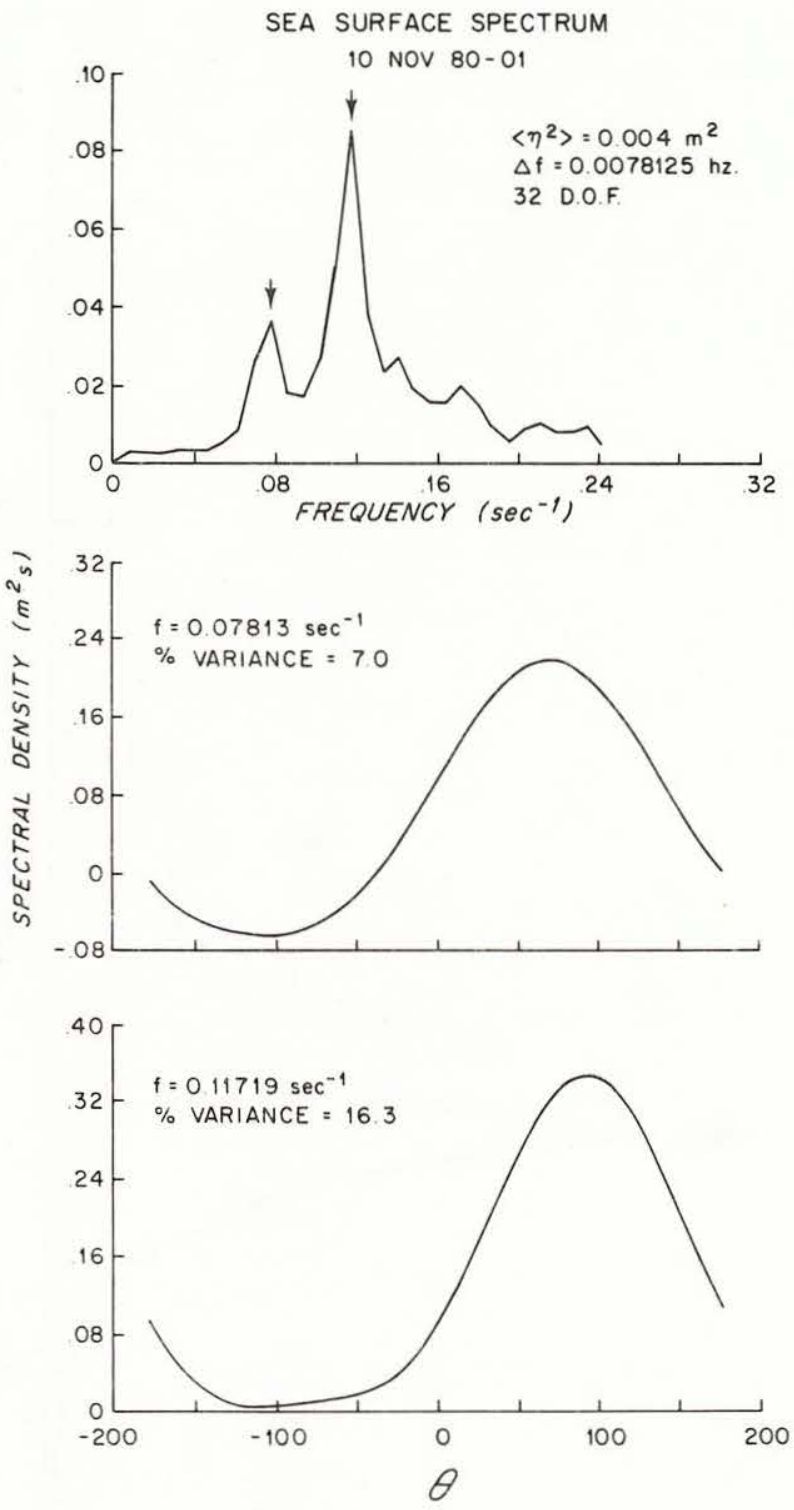

Figure 8: (a) Depth-corrected frequency spectrum for 10 November 1980 (0100 hrs), calculated from u, v. Peaks are near 13 seconds and 8.5 seconds.

(b) Directional spectrum at frequency $=0.07813 \mathrm{hz}$. $\phi=94^{\circ}$ (direction waves are coming from) and directional spread is $52^{\circ}$. Units of energy are relative. (c) Directional spectrum at frequency $=0.11719 \mathrm{hz}$. $\phi=960$ (direction waves are coming from) and directional spread is 390 . Units of energy are relative. 


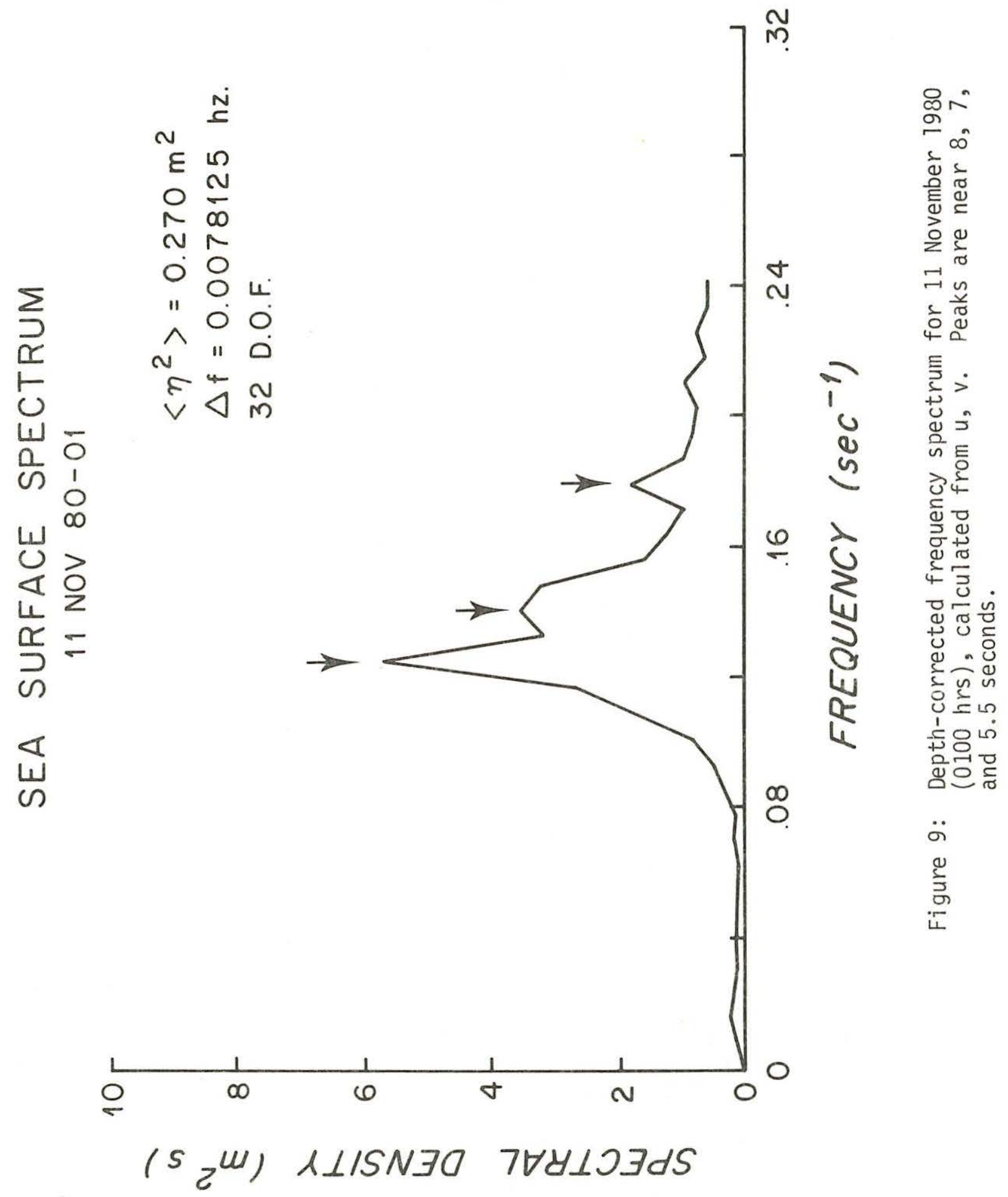



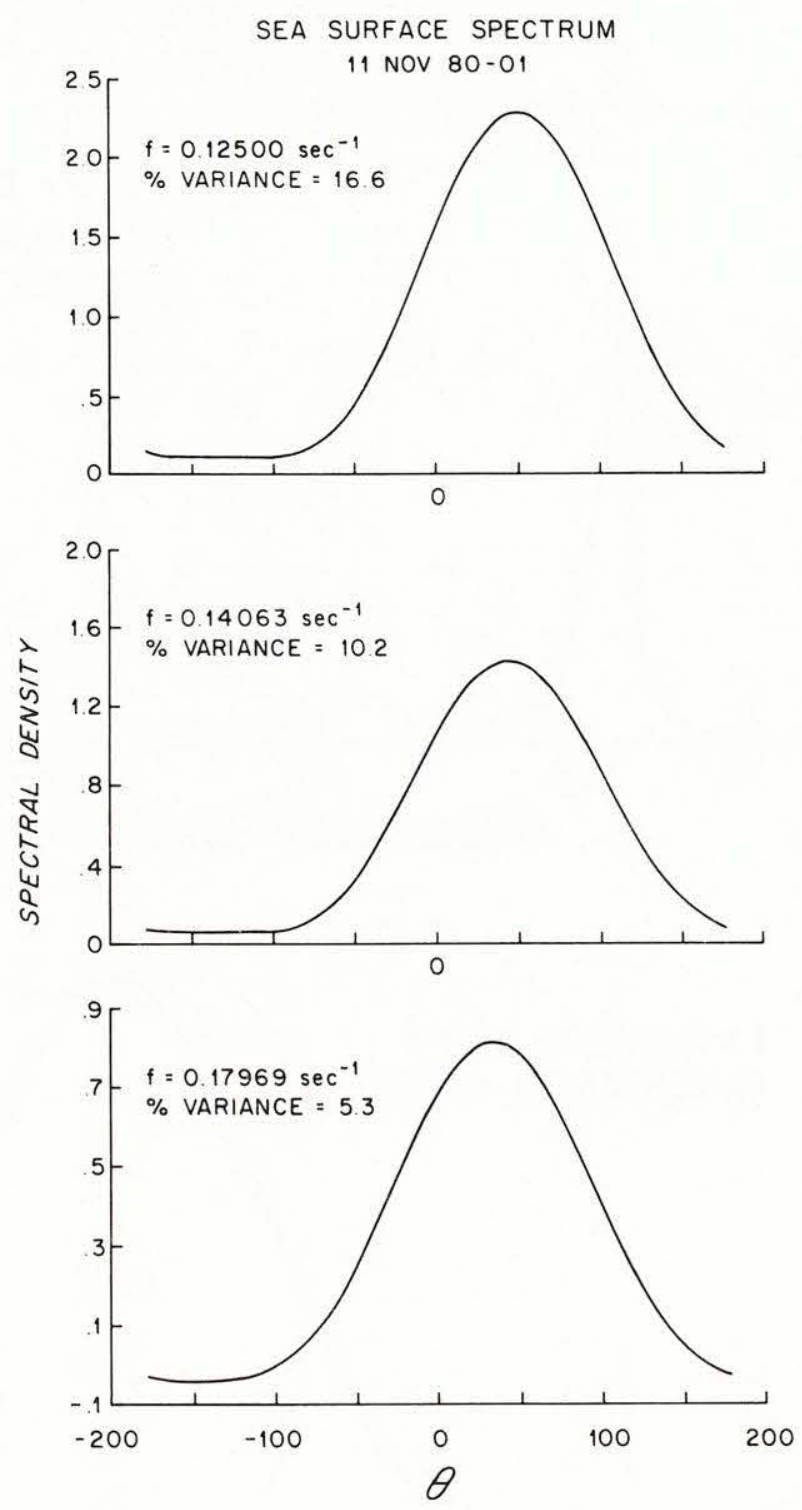

Figure 10: (a) Directional spectrum for 11 November 1980 (0100 hrs), for frequency $=0.125 \mathrm{hz} . \phi=52^{\circ}$ (direction waves are coming from) and directional spread is $22^{\circ}$. A11 directional energy densities are relative.

(b) Directional spectrum for frequency $=0.14063 \mathrm{hz}$. $\phi=42^{\circ}$ and directional spread is 240 .

(c) Directional spectrum for frequency $=0.17969 \mathrm{hz}$. $\phi=36^{\circ}$ (direction waves are coming from) and directional spread is $17^{\circ}$. 


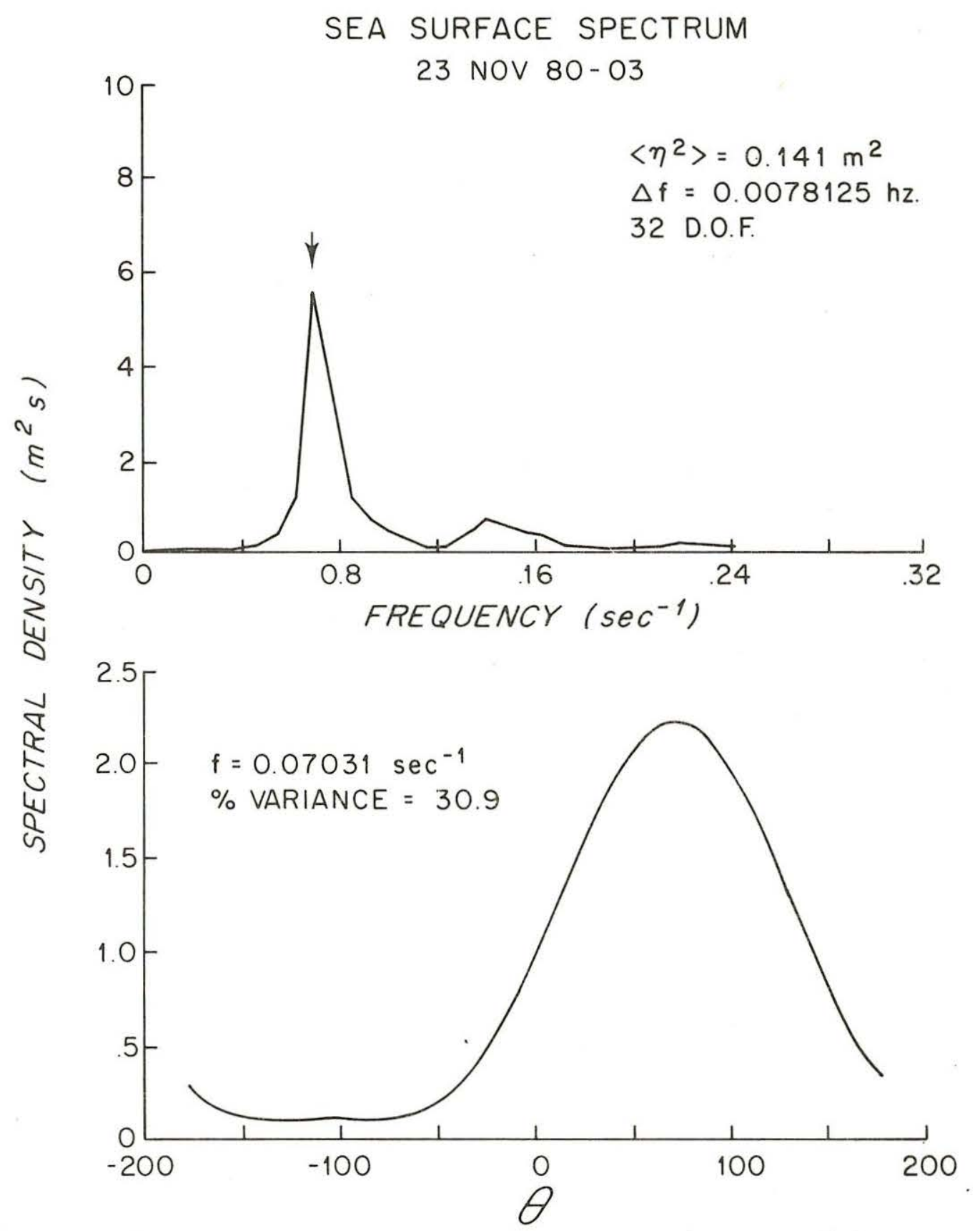

Figure 11: (a) Depth-corrected frequency spectrum for 23 November 1980 ( $1300 \mathrm{hrs}$ ), calculated from u, v. Peak is narrow-band, centered near 14 seconds.

(b) Directional spectrum at frequency $=0.07031 \mathrm{hz}$. $\phi=70^{\circ}$ (direction waves are coming from) and directional spread is $20^{\circ}$. Energy units are relative. 


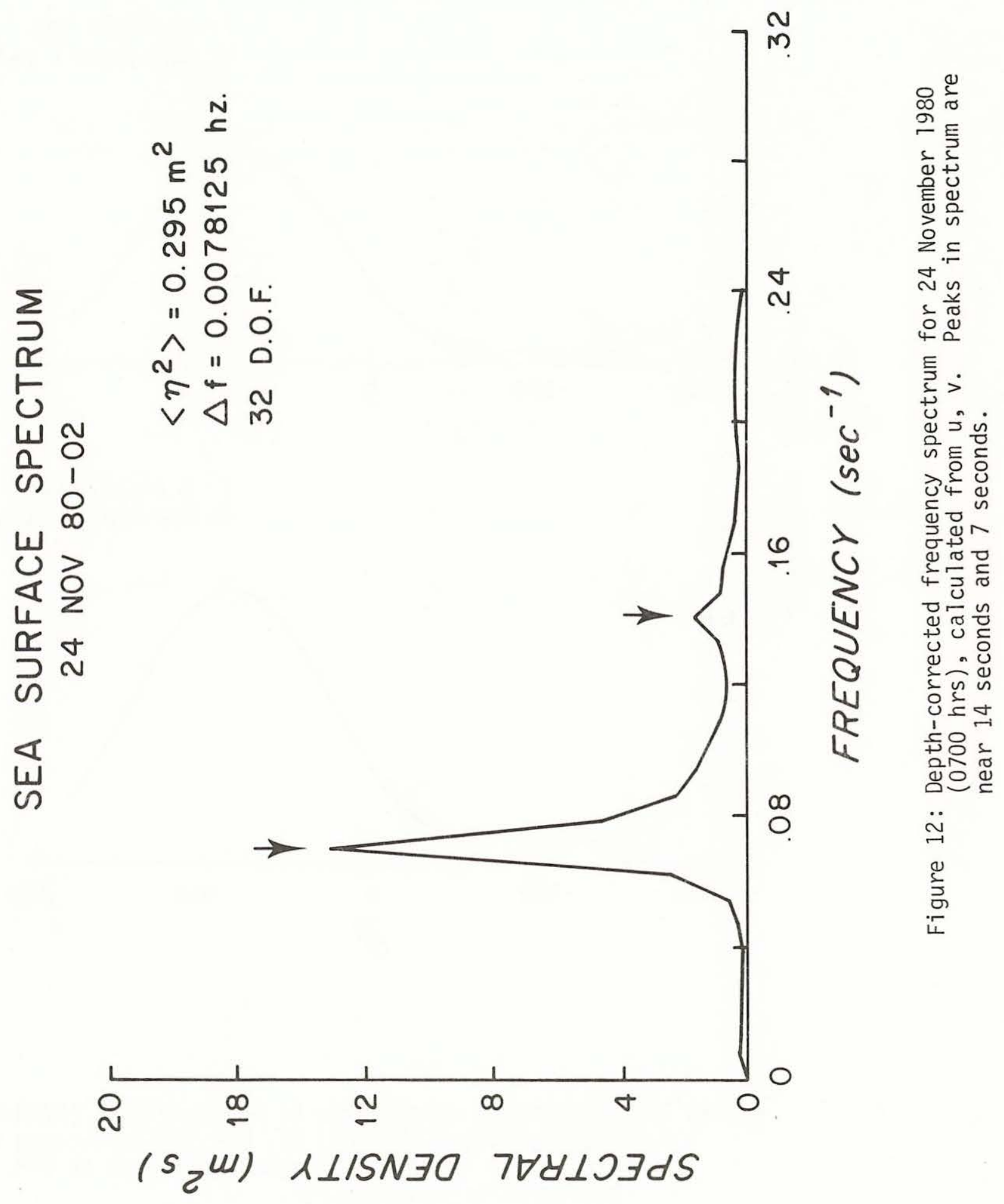




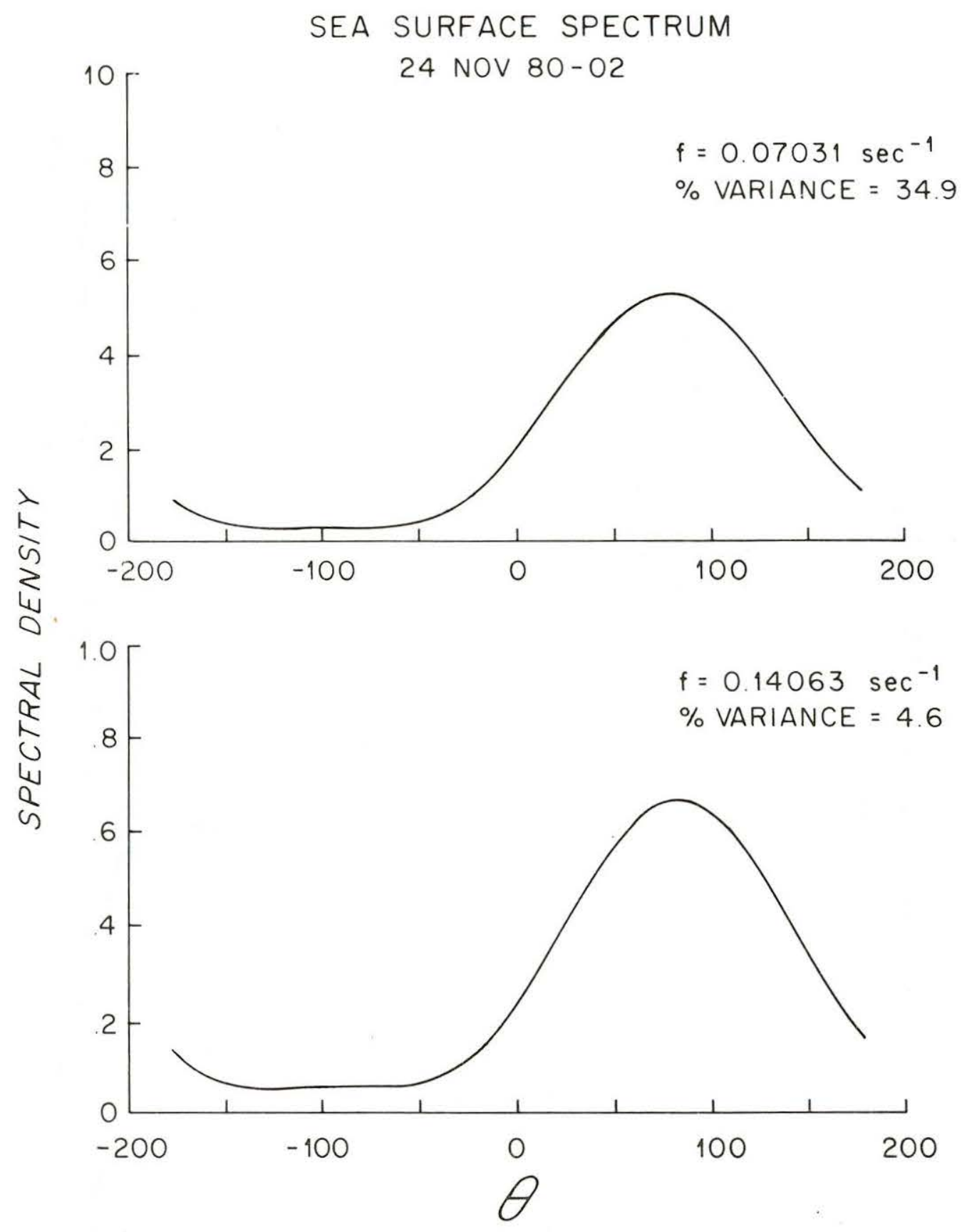

Figure 13: Directional spectra for 24 November 1980 (0700 hrs). (a) Frequency $=0.07031 \mathrm{hz}, \phi=790$ (direction waves are coming from) and directional spread is $24^{\circ}$. Energy units are relative.

(b) Frequency $=0.14063 \mathrm{hz}, \phi=78^{\circ}$ (direction waves are coming from) and directional spread is $27^{\circ}$. 
Future work with the data from this study will include quantitative comparisons of the directional estimates with the results from the slope array (CERC), a Marsh McBirney model 585 directional wave gage operated by CERC, surface imaging radar obtained by CERC, a three-axis acoustic current meter deployed by the Norwegian Hydrodynamic Laboratory (Trondheim, Norway), several CERC current meters and Baylor wave gages mounted on the FRF, and a University of Florida three element pressure sensor array. In addition to directional wave measurements, mean flow time histories will also be intercompared, with a microwave radar technique developed by the Naval Research Laboratory included in this intercomparison.

In addition, data adaptive techniques are being applied to increase the resolution of the directional estimates. In order to test the applicability of linear wave theory to shoaling waves in 7 meters water depth, phase differences between $p, u$, and $v$ will be routinely computed. The question of wave field stationarity will be preliminarily evaluated by examining how wave statistics change between a 2048 second wave record, and a 1024 second record embedded within it. Acknow ledgements

The instrument was constructed by Sea Data Corporation of Newton, Massachusetts, under the guidance of Mr. Winfield Hill. Funds for performing the field study were provided by Exxon Research Production Research Company under Technical Services Agreement PR-6520 to Sea Data, Inc. The purchase of the instrument, program development, and 
data analysis were supported by the Department of Commerce, NOAA Office of Sea Grant under Grant numbers NA79AA-D-00102 and NA80AA-D-00077, and by the U.S. Army Research Office.

The diligence of Wayne Spencer in testing, calibrating, deploying and retrieving the instrument under highly adverse conditions is gratefully acknowledged. Dr. Robert Guza and Mr. Paul Cunningham of the Shore Processes Laboratory, Scripps Institution of Oceanography, loaned us a Marsh MCBirney current meter for ARSLOE when our current meter malfunctioned. Pam Barrows typed the several drafts of this report. Dr. R.J. Seymour and his associates kindly provided us with wave estimates calculated from the pressure sensor slope array. Special thanks are given to the staff of the CERC Field Research Facility (under the direction of Curt Mason), for their energetic and cooperative support of field operations associated with this data acquisition effort.

This work benefitted from the cooperation of the many participants in ARSLOE, which was hosted jointly by the U.S. Army Corps of Engineers and the National Oceanic and Atmospheric Administration. 


\section{REFERENCES}

Aubrey, D.G., 1979. Sediment transport in a tidal inlet. WHOI Sea Grant proposal number $\mathrm{R} / \mathrm{B}-21$.

Aubrey, D.G., 1981. A field and laboratory comparison of two shallow water electromagnetic current meters. In preparation.

Cartwright, D.E., 1963. The use of directional spectra in studying the output of a wave recorder on a moving ship, in Ocean Wave Spectra, Prentice-Ha11, Inc., p. 203-218.

Longuet-Higgins, M.S., D.E. Cartwright, and N.D. Smith, 1963. Observations of the directional spectrum of sea waves using the motions of a floating buoy, in Ocean Wave Spectra, Prentice-Ha 11, Inc., p. 111-132.

Mardia, K.V., 1972. Statistics of directional data. Academic Press, N.Y., $357 \mathrm{pp}$.

Mattie, M.G. and D.L. Harris, 1979. A system for using radar to record wave direction. U.S. Army Corps of Engineers, Coastal Engineering Research Center Tech. Report 79-1, 50 pp.

Nagata, Y., 1964. The statistical properties of orbital wave motions and their application for the measurement of directional wave spectra. Jour. of the Ocean. Soc. of Japan, v. 19, p. 1-181.

Pawka, S.S., D.L. Inman, R.L. Lowe and L. Holmes, 1976. Wave climate at Torrey Pines Beach, California. U.S. Army Corps of Engineers, C.E.R.C., Tech. paper No. 76-5, 372 pp. 


\section{APPENDIX I}

Summary of results of Sea Data 635-9 data acquired during ARSLOE in October/November, 1980. Listed are run number $(1=0100 \mathrm{EDT}, 2=0700$ EDT, 3 = 1300 EDT, 4 = 1900 EDT); peak frequency; corresponding peak period; subjective indication of peak width in frequency (narrow or broad); total energy variance, $\left\langle\eta^{2}\right\rangle$, in spectrum (numbers in parentheses are variance calculated from current meter, other numbers indicate variance calculated from pressure sensor); approximate variance in peak frequency; direction of propagation of waves in peak frequency (in degrees true north); and angular spread, in degrees, of wave field at peak frequency (low value indicates low directional spread, hence more directed wave train). All data are surface corrected. 
DUCK, N.C.

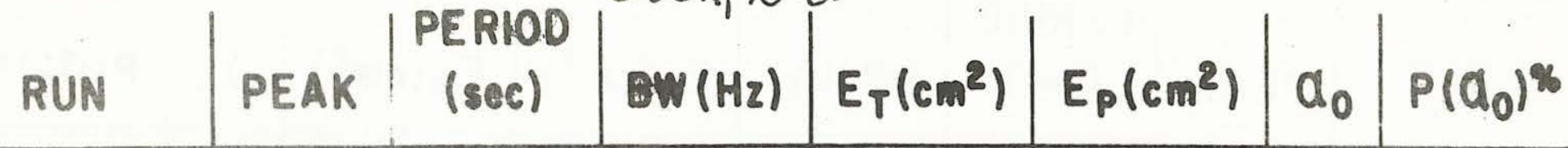

\begin{tabular}{|c|c|c|c|c|c|c|c|}
\hline 31 OCT $80-03$ & .09375 & 10.7 & Namow. & $127(141)$ & 12 & 304 & 39 \\
\hline \multirow[t]{2}{*}{-04} & .08594 & 11.6 & $B R_{0} A D$ & $115(130)$ & 15 & 275 & 44 \\
\hline & .125 & 8.0 & " & & 12 & 269 & 31 \\
\hline \multirow{2}{*}{ INov80-01 } & .08594 & 11.6 & 11 & $98(106)$ & 8 & 262 & 39 \\
\hline & 1172 & 8.5 & "1 & & 10 & 269 & 29 \\
\hline \multirow[t]{2}{*}{-02} & .09375 & 10.7 & 11 & $54(62)$ & 8 & 285 & 40 \\
\hline & & & & & & & \\
\hline-03 & .1094 & 9.1 & 11 & $52(59)$ & 7 & 272 & 40 \\
\hline-04 & .1094 & 9.1 & 11 & $60(69)$ & 9 & 275 & 37 \\
\hline \multirow[t]{2}{*}{$=N 10 v 80-01$} & -1016 & 9.8 & "' & $1040(1113)$ & 13 & 280 & 27 \\
\hline & 1875 & 5.3 & Bropt? & & 75,5 & 212 & 17 \\
\hline-02 & 1523 & 6.6 & $B R D$ & $849(917)$ & 266 & 219 & 20 \\
\hline-03 & .14063 & 7.1 & 11 & $604(640)$ & 213 & 241 & 26 \\
\hline \multirow[t]{2}{*}{-04} & .1641 & 61 & 11 & $290(312)$ & 45 & 233 & 29 \\
\hline & 2109 & 4.7 & $\therefore$ & & 30 & 220 & 28 \\
\hline 3 Nov $80-01$ & 1563 & 6.4 & & $254(285)$ & 32 & 250 & 29 \\
\hline \multirow[t]{2}{*}{-02} & .1016 & 9.8 & & $151(182)$ & 11 & 273 & 28 \\
\hline & .1641 & 6.1 & & & 15 & 233 & 33 \\
\hline & & & & & & & \\
\hline \multirow[t]{2}{*}{-03} & .125 & 8.0 & & $155(191)$ & 16 & 267 & 28 \\
\hline & -1875 & $5-3$ & & & 4 & 257 & 29 \\
\hline-04 & 1155 & 9.5 & & $118(100)$ & 18 & 275 & 40 \\
\hline \multirow[t]{2}{*}{$4 \times 10 \times 80-01$} & -1094 & $3 \cdot 1$ & & $142(180)$ & 16 & 272 & 27 \\
\hline & & & & & & & \\
\hline$\ldots 02$ & $.10 / 6$ & 9.8 & & $140(171)$ & 16 & 1262 & 32 \\
\hline
\end{tabular}




\begin{tabular}{|c|c|c|c|c|c|c|c|}
\hline RUN & PEAK & (sec) & $\mathrm{OW}\left(\mathrm{H}_{2}\right)$ & $E_{T}\left(c m^{2}\right)$ & $E_{p}\left(c m^{2}\right)$ & $\alpha_{0}$ & $P\left(a_{0}\right)^{2}$ \\
\hline 4 Nov $80-03$ & .1172 & 8.5 & & $112(125)$ & 18 & 269 & 30 \\
\hline-04 & .1094 & 9.1 & & $175(204)$ & 13 & 269 & 33 \\
\hline 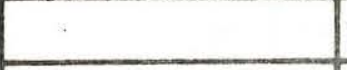 & .1875 & $5-3$ & BROAD & & $20^{\circ}$ & 292 & 23 \\
\hline 5 Nov $80-01$ & .1172 & 8.5 & & $235(261)$ & 29 & 272 & 29 \\
\hline & .1484 & 6.7 & & & 66 & 291 & 30 \\
\hline-02 & .1953 & $5-1$ & & $388(471)$ & 240 & 215 & 25 \\
\hline & & & & & & & \\
\hline-03 & .1758 & 5.7 & & $306(417)$ & 136 & 227 & 23 \\
\hline-04 & 1719 & 5.8 & & $(330)$ & 80 & 234 & 34 \\
\hline 6 Nov8O-OI & .1953 & 5.1 & & $177(200)$ & 22 & 222 & 26 \\
\hline-02 & .1875 & 5.3 & & $505(527)$ & 142 & 218 & 23 \\
\hline-03 & .1094 & 9.1 & & $368(401)$ & 60 & 27 & 32 \\
\hline-04 & .1328 & $7-5$ & & $250(265)$ & 33 & 258 & 31 \\
\hline- & & & & & & & \\
\hline $7 \mathrm{Nov} 80-01$ & -1172 & $8 \cdot 5$ & & $135(143)$ & 25 & 266 & 20 \\
\hline-02 & .08594 & 11.6 & & $85(84)$ & 12 & 266 & 41 \\
\hline-03 & .1133 & 8.8 & & $122(105)$ & 26 & 278 & 39 \\
\hline-04 & .1172 & 8.5 & & $100(109)$ & 15 & 260 & 29 \\
\hline 8 Nov $80-01$ & .1211 & 8.3 & & $68(73)$ & 14 & 2,70 & 29 \\
\hline & & & & & & & \\
\hline-02 & .1094 & 9.1 & & $43(46)$ & 4 & 272 & 32 \\
\hline-03 & .1484 & 6.7 & & $57(44)$ & 6 & 294 & 47 \\
\hline-04 & .1445 & 6.9 & & $44(43)$ & 8 & 288 & 43 \\
\hline
\end{tabular}




\begin{tabular}{|c|c|c|c|c|c|c|c|}
\hline RUN & PEAK & $(\mathrm{sec})$ & $\mathbb{B W}\left(\mathrm{Hz}_{2}\right)$ & $E_{T}\left(\mathrm{~cm}^{2}\right)$ & $E_{p}\left(\mathrm{~cm}^{2}\right)$ & $a_{0}$ & $P\left(a_{0}\right) \%$ \\
\hline 9 Nor $80-01$ & .1211 & 8.3 & & $43(42)$ & 8 & 292 & 35 \\
\hline-02 & .0859 & $11 \cdot 6$ & & $52(47)$ & 4 & 281 & 50 \\
\hline-03 & .1016 & 9.8 & & $56(68)$ & 14 & 263 & 41 \\
\hline-04 & .1094 & 9.1 & & $94(81)$ & 11 & 270 & $44^{\circ}$ \\
\hline $10 \mathrm{NCV} 80-01$ & .1172 & 8.5 & & $60(42)$ & 7 & 276 & 39 \\
\hline-02 & 07013 & 178 & & $57(54)$ & 7 & 270 & 17 \\
\hline & & & & 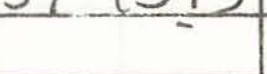 & & & \\
\hline-23 & .07813 & 12.8 & & $41(57)$ & 7 & 253 & 45 \\
\hline & & 1 & & & & & \\
\hline-04 & .1953 & 5.1 & & $452(445)$ & 118 & 201 & 26 \\
\hline & 2yer & $4-7$ & & & 218 & 201 & 29 \\
\hline 11 Nor $80-01$ & .125 & 8.0 & BROAD & $2400(2706)$ & 1799 & 232 & 22 \\
\hline & .1797 & 5.6 & & & 300 & 216 & 17 \\
\hline-02 & .1484 & 6.7 & $"$ & $1746(1870)$ & 1057 & 2220 & 21 \\
\hline & & & & & & & \\
\hline-03 & .1328 & 7.5 & 11 & $1102(1183)$ & 300 & 230 & 24 \\
\hline-04 & .1484 & 6.7 & & $941(973)$ & 228 & 228 & 23 \\
\hline $12 N C \times 80-01$ & .1094 & 9.1 & & $1447(1628)$ & 364 & 242 & 32 \\
\hline & .1406 & 7.1 & BPOAD & & 340 & 230 & 23 \\
\hline-02 & .1172 & 8.5 & & $1832(1959)$ & 192 & 239 & 23 \\
\hline & .01406 & 7.1 & & & 495 & 223 & 22 \\
\hline$=$ & & 1 & & & & & \\
\hline-03 & 1328 & 7.5 & & $1526(1629)$ & 331 & 230 & $\therefore 2$ \\
\hline & .1484 & 6.7 & & & 347 & 225 & 21 \\
\hline-04 & .1484 & 6.7 & & $965(994)$ & 251 & 230 & 20 \\
\hline & & & & & & & \\
\hline
\end{tabular}




\begin{tabular}{|c|c|c|c|c|c|c|c|}
\hline RUN & PEAK & $(\sec )$ & $\mathrm{BW}\left(\mathrm{H}_{2}\right)$ & $E_{T}\left(c m^{2}\right)$ & $E_{p}\left(c m^{2}\right)$ & $\alpha_{0}$ & $P\left(a_{0}\right) \%$ \\
\hline 13 Nor $80-01$ & .1484 & 6.7 & Narfow & $1128(1138)$ & 252 & 227 & 19 \\
\hline-02 & 1172 & 8.5 & $\therefore \quad 1$ & $1003(1034)$ & 75 & 250 & 30 \\
\hline & 1563 & 6.4 & BROAD & & 311 & 227 & 21 \\
\hline & & & & & & & \\
\hline-03 & .1172 & 8.5 & BROAD & $597(608)$ & 75 & 251 & 30 \\
\hline & 1328 & 7.5 & 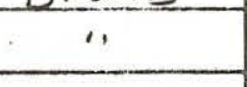 & & 75 & 236 & 27 \\
\hline & & & & & & & \\
\hline-04 & .1016 & 9.8 & Nanow & $482(486)$ & 184 & 246 & 36 \\
\hline & & & & & & & \\
\hline 14 Nor $80-01$ & .0938 & 10.7 & 11 & $386(391)$ & 227 & 270 & 33 \\
\hline & & & & & & & \\
\hline-02 & .0977 & 10.2 & 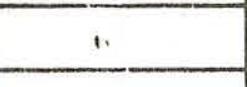 & $239(232)$ & 103 & 262 & 22 \\
\hline & & & & & & & \\
\hline-03 & .1016 & 9.8 & 11 & $182(164)$ & 53 & 264 & 30 \\
\hline & & & & & & & \\
\hline-04 & .0977 & 10.2 & Broad & $99(104)$ & 33 & 260 & 30 \\
\hline 15 Nov $80-01$ & .10156 & 9.8 & 11 & $71(64)$ & 11 & 263 & 35 \\
\hline & & & & & & & \\
\hline-02 & .08594 & 11.6 & 11 & $50(57)$ & 19 & 274 & 46 \\
\hline & & & & & & & \\
\hline-03 & .08594 & 11.6 & 11 & $41(41)$ & 14 & 259 & 53 \\
\hline-04 & .0938 & -10.7 & 11 & $41(46)$ & 14 & 254 & 40 \\
\hline & & & & & & & \\
\hline $16 \times 10 \times 80-01$ & .1875 & 5.3 & 11 & $184(215)$ & 52 & 217 & 33 \\
\hline-02 & .1641 & 6.1 & 11 & $1862(2014)$ & 1255 & 227 & 19 \\
\hline & & & & & & & \\
\hline-03 & .1406 & 7.1 & 11 & $1480(1475)$ & 380 & 250 & 28 \\
\hline & .1563 & 6.4 & 11 & & 374 & 241 & 25 \\
\hline & & & & & & & \\
\hline-04 & .1406 & 7.1 & "1 & $1142(1145)$ & 349 & 240 & 20 \\
\hline 17 Nov $80-01$ & .1367 & 7.3 & & $911(903)$ & 226 & 243 & 28 \\
\hline & & & & & & & \\
\hline
\end{tabular}




\begin{tabular}{|c|c|c|c|c|c|c|c|}
\hline RUN & PEAK & $(\mathrm{sec})$ & $\mathrm{BW}\left(\mathrm{H}_{2}\right)$ & $E_{T}\left(c m^{2}\right)$ & $E_{p}\left(\mathrm{~cm}^{2}\right)$ & $\alpha_{0}$ & $P\left(a_{0}\right)^{\%}$ \\
\hline 17 Nov $80-02$ & 1406 & 7.1 & BROAD & $662(662)$ & 215 & 240 & 20 \\
\hline$-0,3$ & 1328 & 7.5 & VERY BROAD & $856(855)$ & 176 & 750 & 24 \\
\hline & .1308 & & 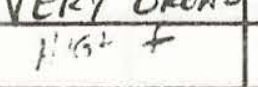 & & & 200 & \\
\hline-04 & .17188 & 5.8 & & $843(842)$ & 175 & 252 & 21 \\
\hline 18 Nor $80-01$ & 1484 & 6.7 & Beof & $1293(1246)$ & 735 & 272 & 21 \\
\hline-02 & 1172 & 8.5 & 11 & $1013)$ & 517 & 276 & 26 \\
\hline & & & & & & & \\
\hline-03 & .1016 & 9.8 & 11 & $480(460)$ & 96 & 278 & 28 \\
\hline & .1172 & 8.5 & 11 & & 111 & 275 & 24 \\
\hline & & & & & & & \\
\hline-04 & .1641 & 6.1 & 1 & $1259(1263)$ & 446 & 218 & 21 \\
\hline 19 Nov $80-01$ & .1406 & 7.1 & 11 & $1802(1830)$ & 971 & 230 & 21 \\
\hline & & & & & & & \\
\hline-02 & .1328 & 7.5 & 11 & $1337(1386)$ & 505 & 231 & 26 \\
\hline-03 & 125 & 00 & 1. & $943(044)$ & $11=$ & 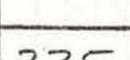 & 37 \\
\hline$-0=$ & .125 & 71 & $\because$ & $170(197)$ & $\frac{163}{159}$ & 244 & $\frac{27}{25}$ \\
\hline & & & & & & & \\
\hline-04 & .1094 & 9.1 & 11 & $543(530)$ & 112 & 239 & 34 \\
\hline & .1328 & 7.5 & 11 & & 103 & 237 & 25 \\
\hline & & & & & & & \\
\hline 20 Nor $80-01$ & .10156 & 9.8 & 1 & $(385)$ & 60 & $24 L$ & 35 \\
\hline & .1225 & 25 & ". & & 58 & 243 & 55 \\
\hline-02 & 0859 & $11 / 6$ & & $(A<2)$ & 182 & $-4 ?$ & 10 \\
\hline$=02$ & .0821 & 11.6 & & & & & 40 \\
\hline-03 & .0859 & 11.6 & 7 & $(5 / 3)$ & 175 & 252 & 36 \\
\hline 1 & & & & & & & \\
\hline-04 & .0859 & 116 & 11 & $(4 / 3)$ & 165 & 260 & 37. \\
\hline 21 Nov $80-01$ & .0938 & 10.7 & "1 & $(560)$ & 208 & 266 & 38 \\
\hline & & & & & & & \\
\hline-02 & .0859 & 11.6 & ". & $(522)$ & 244 & 263 & 54 \\
\hline
\end{tabular}




\begin{tabular}{|c|c|c|c|c|c|c|c|}
\hline RUN & PEAK ! & $(\sec )$ & $\mathrm{ON}\left(\mathrm{H}_{z}\right)$ & $E_{T}\left(c m^{2}\right)$ & $E_{p}\left(c m^{2}\right)$ & $\alpha_{0}$ & $P\left(a_{0}\right)^{*}$ \\
\hline $21 N_{0 V} 80-03$ & .0859 & 11.6 & Narrow & $(341)$ & 102 & 254 & 32 \\
\hline \multirow[t]{2}{*}{-04} & .0781 & 12.8 & BROAD & $(523)$ & 74 & 270 & 47 \\
\hline & 1797 & $5 \cdot 6$ & 1, & & 83 & 232 & 66 \\
\hline $22 N 0.80-01$ & .1875 & $5 \cdot 3$ & 1. & (637) & 163 & 249 & 110 \\
\hline-02 & .1484 & 6.7 & 11 & $994(1096)$ & 510 & 229 & 26 \\
\hline \multirow[t]{2}{*}{-03} & .1719 & 5.8 & 11 & $468(567)$ & 148 & 228 & 19 \\
\hline & & & & & & & \\
\hline-04 & .1719 & 5.8 & 11 & $312(396)$ & 108 & 220 & 32 \\
\hline \multirow[t]{2}{*}{23 Nor $80-01$} & .0625 & 16.0 & NARROW & $196(270)$ & 38 & 247 & 42 \\
\hline & .1719 & 5.8 & BroN & & 44 & 247 & 34 \\
\hline-02 & .0625 & 16.0 & 11 & $195(267)$ & 51 & 251 & 42 \\
\hline-03 & .0703 & 14.2 & NARROW & $1232(1411)$ & 792 & 250 & 26 \\
\hline \multirow[t]{2}{*}{-04} & .0703 & 14.2 & 11 & $2437(2509)$ & 1381 & 255 & 28 \\
\hline & .1406 & 7.1 & BROAD & & 219 & 256 & 25 \\
\hline \multicolumn{8}{|c|}{ 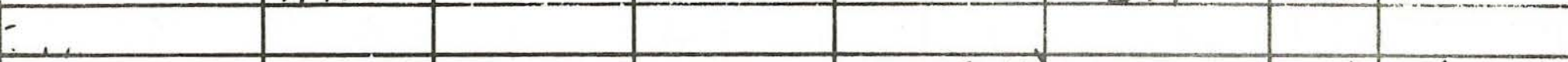 } \\
\hline \multirow[t]{2}{*}{$24 \times 10 \times 80-01$} & .0625 & 16 & NARROW & $2255(2496)$ & 1187 & 254 & 26 \\
\hline & .1328 & 7.5 & BROAD & & 285 & 247 & 30 \\
\hline \multirow[t]{2}{*}{-02} & .0703 & 14.2 & NARROW & $2633(296)$ & 1779 & 259 & 24 \\
\hline & .1406 & 7.1 & BeOKD & & 279 & 258 & 27 \\
\hline & & & & & & & \\
\hline & & & & & & & \\
\hline & & & & & & & \\
\hline & & & & & & & \\
\hline & & & & & & & \\
\hline & & & & & & & \\
\hline & & & & & & & \\
\hline & & & & & & & \\
\hline
\end{tabular}




\section{APPENDIX II}

Summary of frequency spectra (band-averaged to yield equal period bands) calculated from slope array to which the Sea Data 635-9 was attached. Local time is PDT, so three hours must be added to obtain EDT, for comparison with Appendix I. Data provided by Dr. R.J. Seymour. 


\section{WAVE ENERGY SPECTRA NOV 1980}

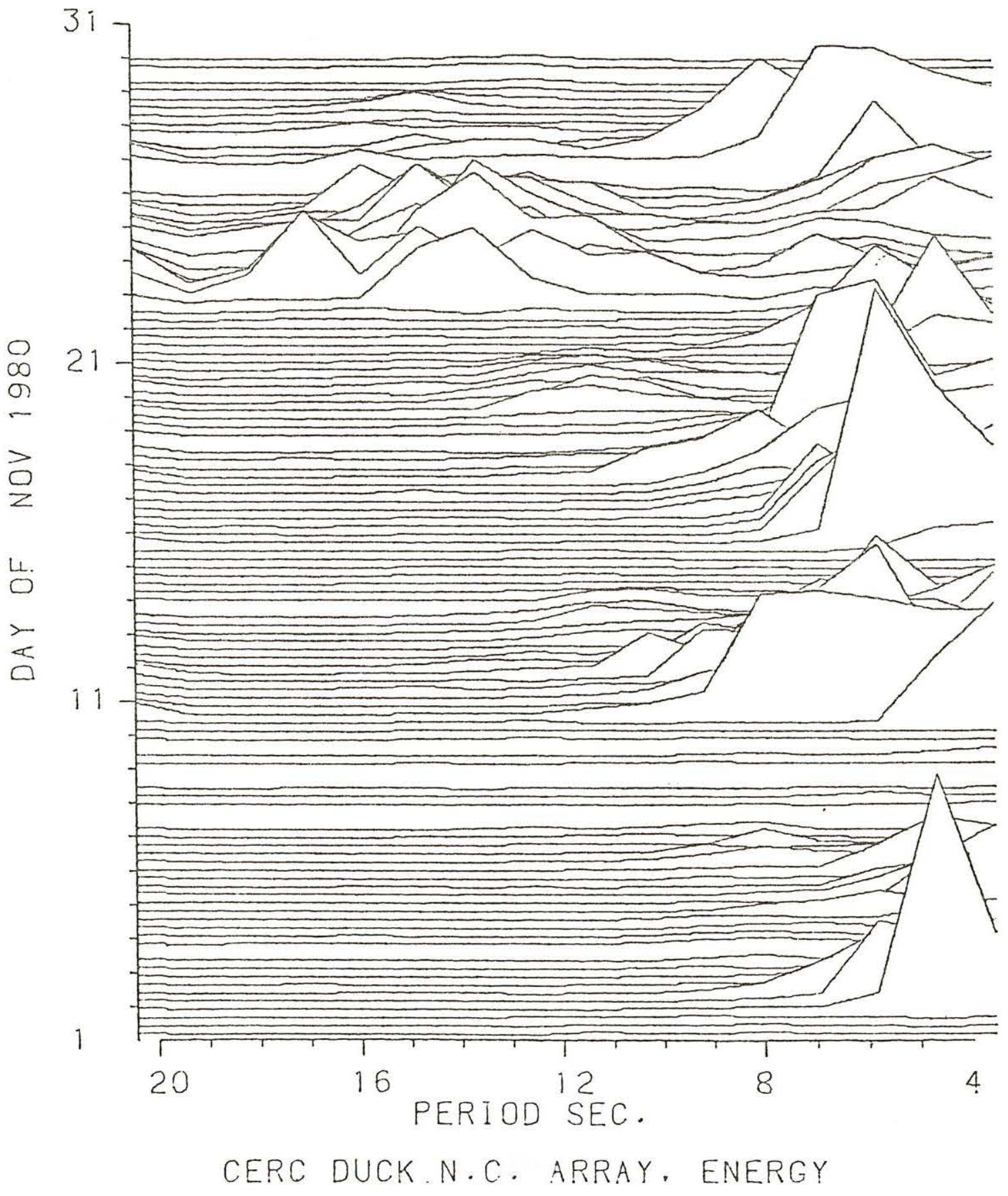


CERC DUCK N. C. ARRAY, ENERGY

NOV 1980

LOCAL SIG. HT TOT. EN DAY/TIME (CM.) (CM. SQ)
PERCENT ENERGY IN BAND

(TDTAL ENERGY INCLUDES RANGE 204B-4 SECS) BAND PERIOD LIMITS (SECS)

$22+22-18 \quad 18-16 \quad 16-14 \quad 14-12 \quad 12-10 \quad 10-8 \quad 8-6 \quad 6-4$

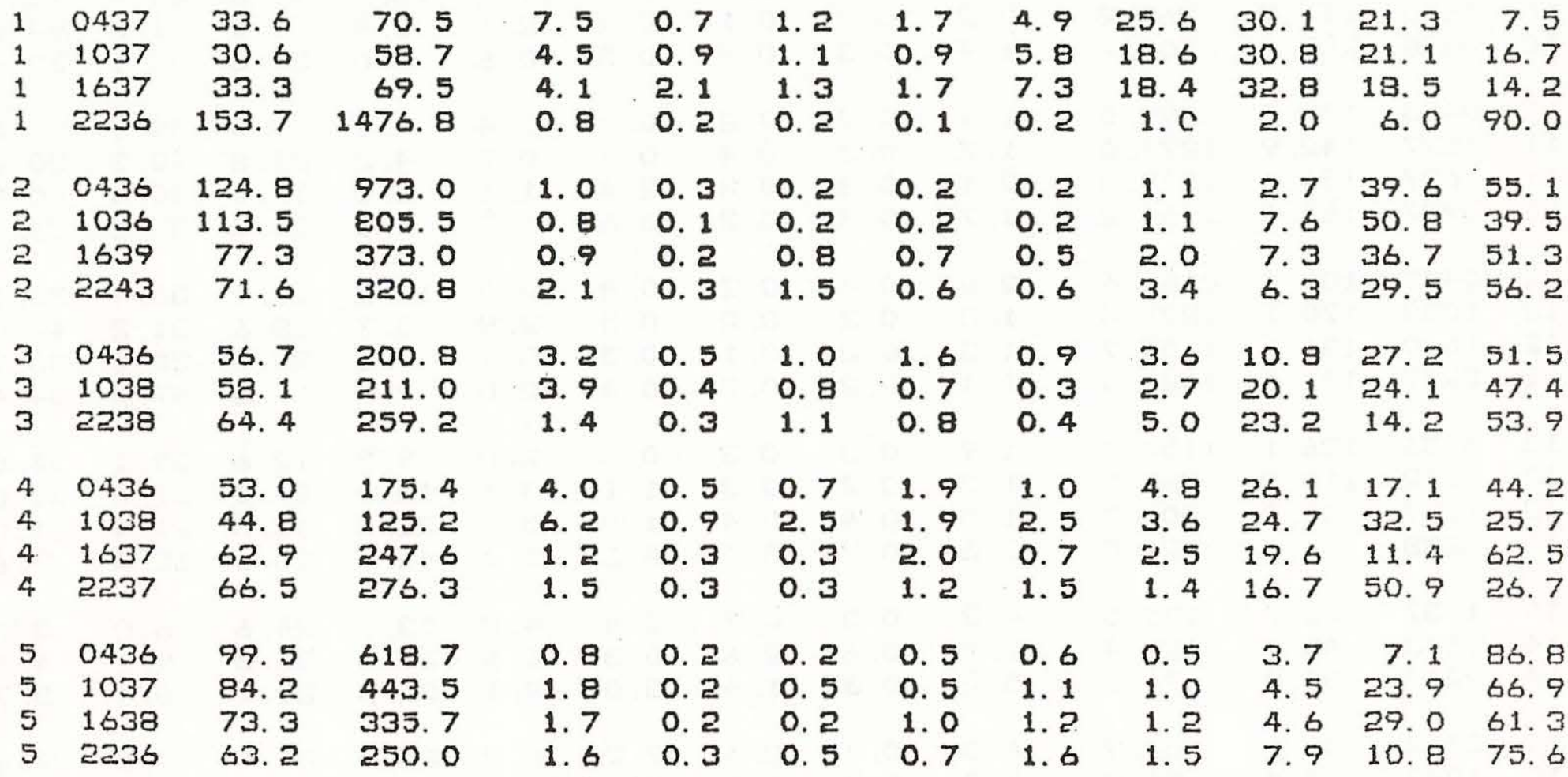

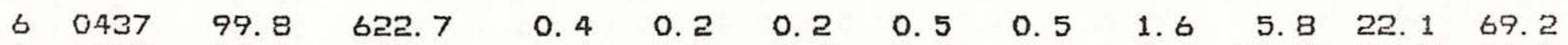

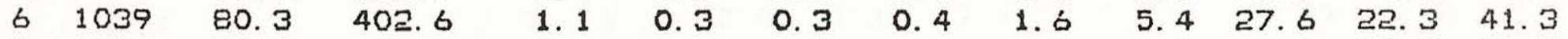

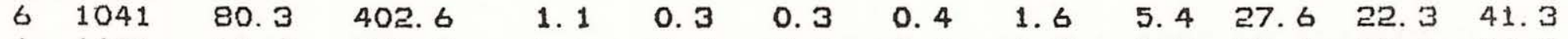

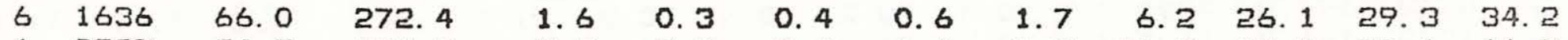

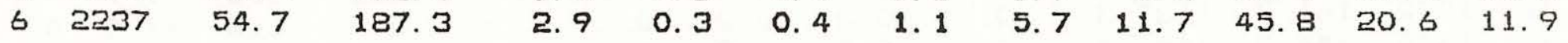

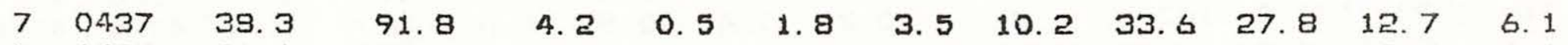

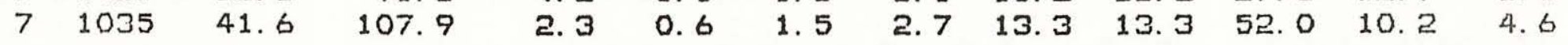

$\begin{array}{lllllllllllll}8 & 0436 & 29.9 & 55.8 & 2.4 & 0.6 & 1.0 & 2.3 & 5.1 & 6.7 & 25.0 & 17.9 & 39.4 \\ 8 & 1044 & 37.2 & 86.6 & 1.8 & 0.7 & 1.6 & 2.8 & 4.7 & 5.8 & 10.4 & 45.2 & 27.5\end{array}$

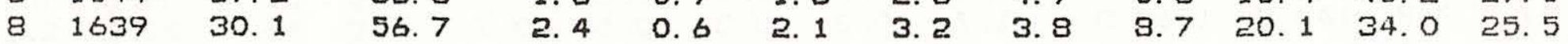

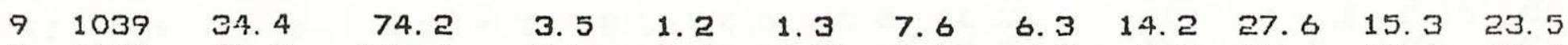

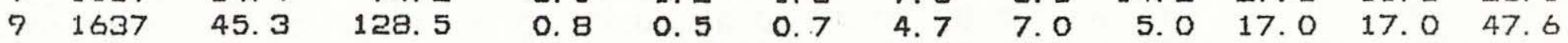

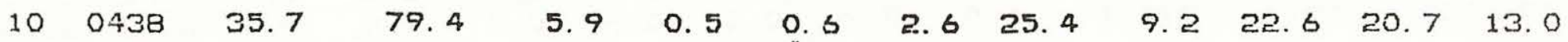


CERC DUCK N.C. ARRAY, ENERGY

NOV 1780

LOCAL SIG. HT TOT. EN DAY/TIME (CM.) (CM. SQ)

$\begin{array}{llll}10 & 1039 & 29.7 & 55.0\end{array}$

$10 \quad 1635 \quad 117.9 \quad 868.2$

$\begin{array}{llll}10 & 2238 & 208.1 & 2705.7\end{array}$

$\begin{array}{llll}11 & 0435 & 178.9 & 1999.5\end{array}$

$\begin{array}{llll}11 & 1037 & 142.9 & 1277.0\end{array}$

$11 \quad 1637 \quad 131.4 \quad 1079.0$

$\begin{array}{llll}112237 & 168.0 & 1764.2\end{array}$

$120437 \quad 183.4 \quad 2101.6$

$\begin{array}{llll}12 & 1039 & 170.1 & 1807.8\end{array}$

$\begin{array}{llll}12 & 1540 & 136.1 & 1157.7\end{array}$

$\begin{array}{llll}12 & 2237 & 151.0 & 1425.3\end{array}$

$130436 \quad 136.1 \quad 1157.9$

$13 \quad 1042 \quad 110.5 \quad 762.5$

$\begin{array}{llll}13 & 1537 & 89.9 & 504.7\end{array}$

$132238 \quad 72.0 \quad 324.0$

$\begin{array}{llll}14 & 1037 & 52.7 & 173.5\end{array}$

$\begin{array}{llll}14 & 1643 & 43.9 & 120.4\end{array}$

14. 2242 35. 0 76. 7

$15 \quad 0442$

$15 \quad 1042$

$15 \quad 2242$

16́ $0442 \quad 191.8 \quad 2299.2$

16 1042 161.7 1633. 3

16 1640 154. 0 1482. 4

$\begin{array}{llll}16 & 2237 & 127.8 & 1020.7\end{array}$

\section{17
17
17
18
18
19
19}

$\begin{array}{llll}13 & 0428 & 133.5 & 1114.7\end{array}$

$\begin{array}{llll}18 & 1049 & 90.5 & 511.9\end{array}$

$18 \quad 1726 \quad 131.8 \quad 1085.9$

$\begin{array}{llll}13 & 2251 & 195.6 & 2392.3\end{array}$
PERCENT ENERGY IN BAND

(TOTAL ENERGY INCLUDES RANGE 2048-4 SECS) BAND PERIOD LIMITS (SECS)

$22+22-18$ 18-16 16-14 14-12 $12-10$ 10-8 $8-6$ b-4

$\begin{array}{rrrrrrrrr}2.9 & 1.0 & 1.4 & 8.3 & 19.3 & 12.2 & 19.8 & 20.4 & 15.1 \\ 0.8 & 0.2 & 0.1 & 0.9 & 2.1 & 0.4 & 1.5 & 1.6 & 92.8 \\ 1.9 & 0.3 & 0.2 & 0.3 & 0.6 & 3.0 & 22.8 & 38.1 & 33.4\end{array}$

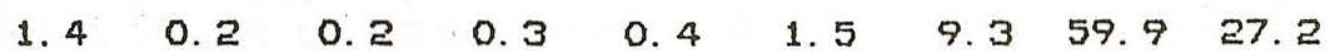

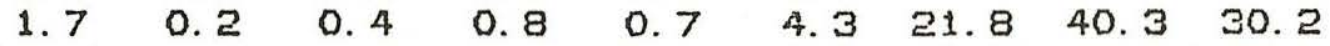

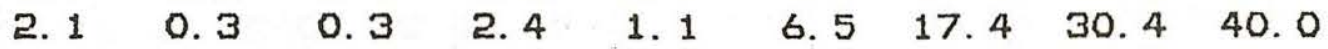

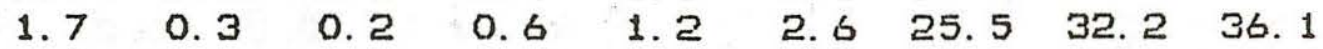

$\begin{array}{lllllllll}2.0 & 0.4 & 0.2 & 0.8 & 2.0 & 10.2 & 17.9 & 36.4 & 30.5\end{array}$

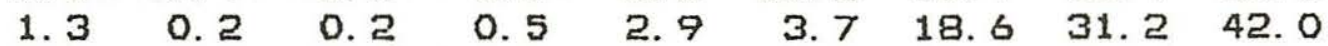

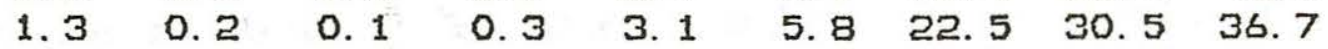

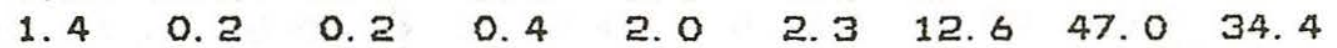

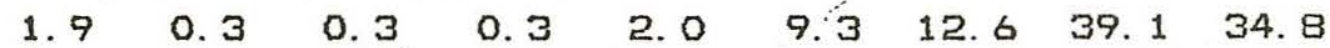

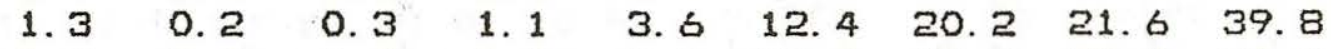

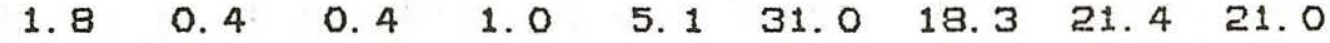

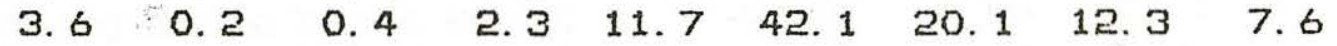

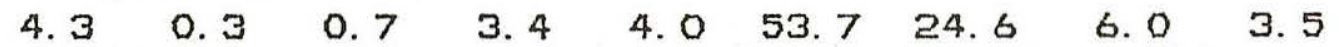

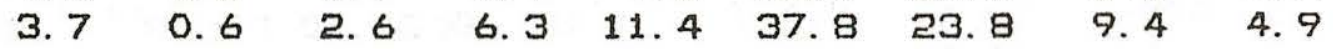

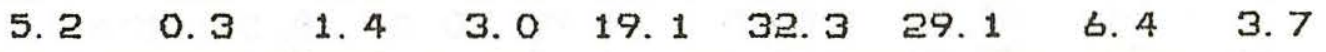

$\begin{array}{lllllllll}4.5 & 0.7 & 2.4 & 7.2 & 20.9 & 26.0 & 21.9 & 9.5 & 7.4\end{array}$

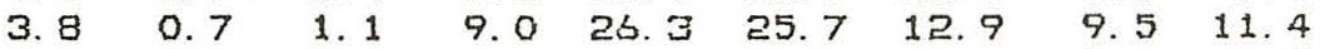

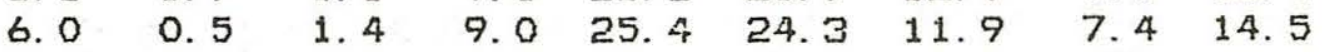

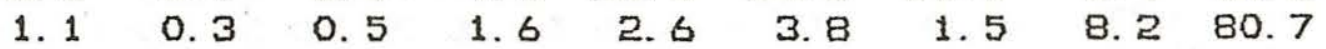

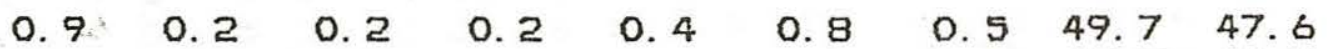

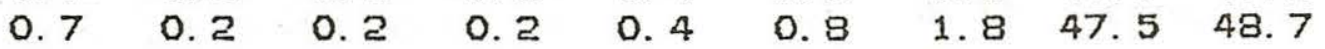

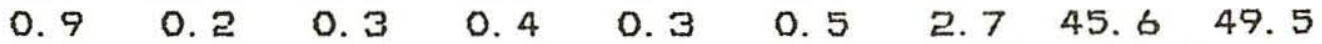

$\begin{array}{lllllllll}0.6 & 0.2 & 0.4 & 0.5 & 0.8 & 0.7 & 4.8 & 43.4 & 49.0\end{array}$

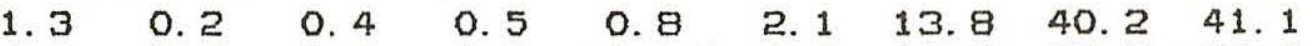

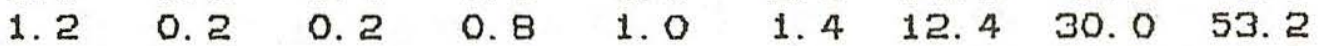

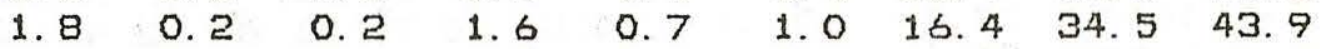

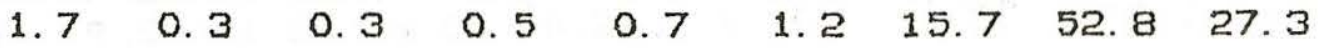

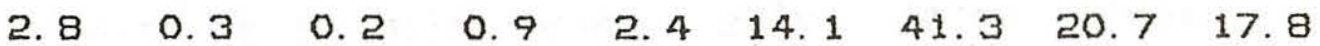

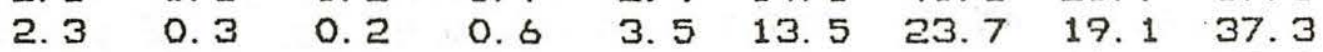

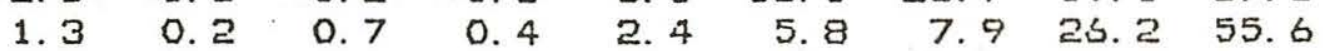

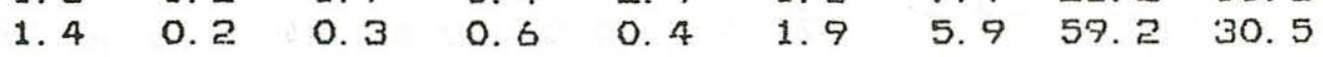


CERC DUCK N.C. ARRAY, ENERGY

NOV 1980

LDCAL SIG. HT TOT. EN DAY/TIME (CM.) (CIV. SQ)

PERCENT ENERGY IN BAND

(TDTAL ENERGY INCLUDES RAINGE 2048-4 SECS) BAND PERIOD LIMITG (SECS)

$22+22-18 \quad 18-16 \quad 16-14 \quad 14-12 \quad 12-10 \quad 10-8 \quad 8-6 \quad 6-4$

\begin{tabular}{|c|c|c|c|c|c|c|c|c|c|c|c|c|}
\hline 17 & 1043 & 134.5 & 1130.6 & 1.9 & 0.2 & 0. 3 & 1.0 & 1.6 & 3.3 & 14. 2 & 36.3 & 41.5 \\
\hline 19 & 1707 & 98.8 & 609.7 & 3. 1 & 0.3 & 0.4 & 0.7 & 3.5 & 4.7 & 20. 1 & 3á. 7 & 31.0 \\
\hline 19 & 2304 & 86.4 & 466.9 & 3.2 & 0.6 & 0.6 & 1.0 & 5.8 & 15. 6 & 13. 6 & 24.8 & 35.2 \\
\hline 0 & 0504 & 97.0 & 588.2 & 3.5 & 0.4 & 0.7 & 1. 8 & 16. 3 & 31.5 & 16. 2 & 10.6 & 19.4 \\
\hline 0 & 1040 & 96.3 & 579.2 & 3.0 & 0.5 & 1. 8 & 2. 8 & 12. 2 & 38.9 & 11.2 & 9. & 20.4 \\
\hline 0 & 1640 & 88. 0 & 484.5 & 3.8 & 0.6 & 0.8 & 3.3 & 21.4 & 28.3 & 13.3 & 12. 1 & 16. 8 \\
\hline 20 & 2240 & 98.3 & 604.0 & 5. 1 & 0.3 & 0.8 & 6.4 & 13.1 & 26. 8 & 21.6 & 11.9 & 14. 4 \\
\hline 1 & 0439 & 87.9 & 483. 1 & 2. 8 & 0.6 & 1.3 & 3. 9 & 18. 4 & 31.9 & 14. 8 & 11.9 & 14. 8 \\
\hline 21 & 1047 & 83.0 & 430.2 & 2. 0 & 0.7 & 1. 4 & 4. 3 & 15. 2 & 28. 8 & 17.2 & 13.9 & 17.0 \\
\hline 21 & 1646 & 104.4 & 680.9 & 1. 5 & 0.5 & 0.6 & 2. 9 & 6.7 & 9.0 & 10.3 & 13. 8 & 55.3 \\
\hline 21 & 2239 & 125.1 & 978.7 & 0. 8 & 0.4 & 0.3 & 0.9 & 1. 5 & 5. 2 & 7.7 & 13. 4 & 70.2 \\
\hline 22 & 0440 & 140.3 & 1230.7 & 0.7 & 0.3 & 0.6 & 0.6 & 1.3 & 2. 1 & 6. 5 & 50.8 & 37.5 \\
\hline 22 & 1040 & 100.8 & 635. 6 & 1. 1 & 0.7 & 1. 1 & 2. 2 & ㄹ. 0 & 2. 0 & 7.6 & 37.1 & 4á. 6 \\
\hline 22 & 1640 & 94.5 & 557.9 & 1. 1 & 0.5 & 1.9 & 2. 0 & 2. 9 & 4. 1 & 5. 4 & 27.9 & 54. 6 \\
\hline כ2 & 2240 & 67.8 & 236.9 & 2. 0 & 0.9 & 5.6 & 8. 2 & 3.7 & 7.3 & 9.2 & 17.0 & 46. 6 \\
\hline 3 & 0440 & 72. 1 & 324.9 & E. 0 & 0. 8 & 6.5 & 10. 2 & 6. 8 & 6. 0 & 8. 1 & 24. 8 & 35.2 \\
\hline 23 & 1037 & 144.1 & 1297. ' & 2. 8 & 1. 0 & 3. 4 & 21.2 & 34.9 & 7.9 & 6. 5 & 13. 6 & 9.2 \\
\hline 23 & 1640 & 199.4 & 2485.0 & 3. 4 & 1. 5 & 18. 6 & 16. 0 & 17.9 & 15. 2 & 7.6 & 11. 0 & 9.3 \\
\hline 3 & 2236 & 196.3 & 2408.7 & 6. 4 & 1.7 & 16.7 & 18. 2 & 9.3 & 14.6 & 7.5 & 16. 1 & 9.7 \\
\hline 4 & 0440 & 191.6 & 2293.8 & 4. 4 & 0. 8 & 1. 6 & 14.6 & 31.7 & 17.7 & 10.0 & 11. 6 & 8. 0 \\
\hline 94 & 1042 & 177.6 & 1971.6 & 4. 7 & 1. 2 & 3.2 & 24.0 & 25.6 & 10.5 & 6. 5 & 14.9 & 9.7 \\
\hline 4 & 2242 & 174.1 & 1893.4 & 3.3 & 0. 7 & 2. 6 & 11.5 & 35.7 & 12. 3 & 8. 7 & 16.6 & 9.0 \\
\hline 5 & 1043 & 171.5 & 1839.2 & 2. 8 & 0.9 & 6.9 & 22. 2 & 16. 0 & 4.6 & 8. 0 & .5 & 24.6 \\
\hline 25 & 1641 & 174.9 & 1912.6 & 2. 7 & 0.8 & 3.3 & 20.8 & 15. 2 & 7.9 & 4.8 & 14. 8 & 30.2 \\
\hline 25 & 2241 & 173.3 & 1877.6 & 2. 1 & 0.4 & 3. 2 & 9.1 & 20. 6 & 6.3 & 4. 3 & 2ㄹ. 0 & 32. 3 \\
\hline 6 & 0441 & 171.8 & 1845.6 & 2. 4 & 0.2 & 2. 0 & 16.8 & 12. 1 & 9.7 & 6. 1 & 22. 3 & 28.8 \\
\hline 26 & 1048 & 156.6 & 1532.5 & 1.6 & 0.8 & 1. 5 & 4.3 & 16. 2 & 6. 5 & 5. 4 & 38.3 & 25.8 \\
\hline 25 & 1709 & 122.1 & 932.1 & 2. 4 & 0.6 & 2. 4 & 14. 3 & 17.4 & 11.9 & 8. 3 & 16.8 & 26. 2 \\
\hline 27 & 1714 & 18. 7 & 2177.7 & 1. 4 & 0.4 & 0.3 & 3. 9 & 3. 8 & 2. 9 & 7.2 & 46. 5 & 33.9 \\
\hline 27 & 2249 & 178.2 & 1984.8 & 2. 7 & 0.5 & 1. 4 & 3. 1 & 8. 1 & 6. 6 & 32.3 & 24.7 & 21. 1 \\
\hline & 0446 & 138.7 & 1202.8 & 2. 4 & 0.6 & 1. 2 & 6.6 & 3.9 & 8. 7 & 27.7 & 28.5 & 20.9 \\
\hline 8 & 1646 & 76.3 & 364.2 & 3. 1 & 0.7 & 6. 2 & 17.3 & 17.3 & 8. 4 & 18. 7 & 21.2 & 5. 5 \\
\hline
\end{tabular}


CERC DUCK N.C. ARRAY, ENERGY
NDV 1980

LOCAL SIG. HT TOT. EN DAY/TIME (CM.) (CM. SQ)

$20 \quad 2243 \quad 53.6 \quad 179.7$

$290444 \quad 53.2 \quad 176.7$

$29 \quad 1042 \quad 55.3 \quad 191.4$

$29 \begin{array}{llll}1641 & 46.3 & 134.2\end{array}$

$\begin{array}{llll}29 & 2307 & 35.1 & 76.9\end{array}$

$\begin{array}{llll}30 & 0444 & 39.9 & 99.3\end{array}$

$\begin{array}{llll}30 & 1640 & 39.1 & 95.7\end{array}$

$30 \quad 2243 \quad 38.5 \quad 92.6$

\section{PERCENT ENERGY IN BAND \\ (TOTAL ENERGY INCLUDES RANGE 2048-4 SECS) BAND PERIOD LIMITS (SECS)}

$22+22-18 \quad 18-16 \quad 16-14 \quad 14-12 \quad 12-10 \quad 10-8 \quad 8-6 \quad 6-4$

$\begin{array}{lllllllll}2.5 & 1.1 & 6.9 & 22.4 & 14.0 & 14.3 & 22.1 & 14.1 & 3.1\end{array}$

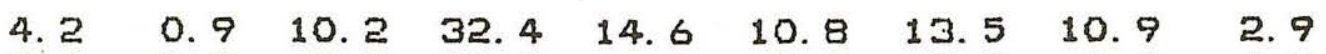

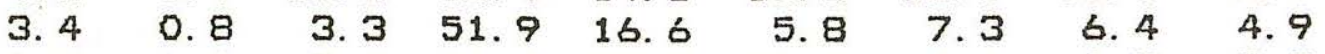

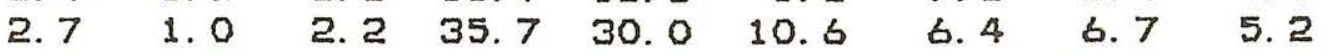

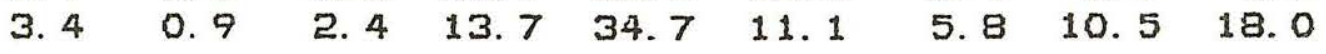

$\begin{array}{lllllllll}3.6 & 2.3 & 1.3 & 7.4 & 42.2 & 12.4 & 7.6 & \text { 8. } 0 & 15.7\end{array}$

$\begin{array}{lllllllll}3.5 & 2.8 & 2.9 & 7.5 & 40.7 & 11.7 & 7.4 & 13.2 & 10.7\end{array}$

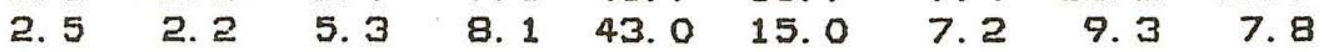


CERC DUCK N.C. ARRAY, ENERGY

NOV 1980

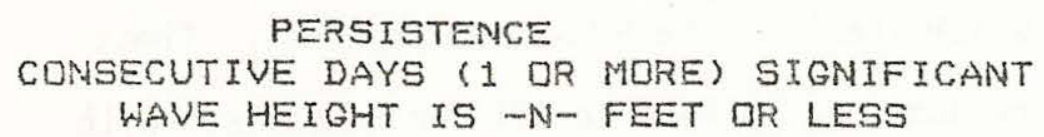

WAVE HEIGHT IS -N-FEET DR LESS

$\begin{array}{cccccc}\text { FEET } & \text { DAYS } & & & & \\ 1 & 3, & 1, & & & \\ 2 & 2, & 3, & 2, & 2, & \\ 3 & 7, & 2, & 1, & 2, & \\ 4 & 8, & 3, & 3, & 2, & \\ 5 & 9, & 3, & 1, & 4, & 3, \\ 6 & 9, & 12, & 7, & & \\ 7 & 30, & & & & \\ 8 & 30, & & & \\ 9 & 30, & & & \\ 10 & 30, & & & \\ 11 & 30, & & & & \\ 12 & 30, & & & \end{array}$

MAXIMUM DAILY SIGNIFICANT WAVE HEIGHT FOR NOV 1980

\begin{tabular}{llrrrrrr} 
DATE ( NOV) & 1 & 2 & 3 & 4 & 5 & 6 & 7 \\
\hline SIG.HT (FT. ) & 5.0 & 4.1 & 2.1 & 2.2 & 3.3 & 3.3 & 1.4
\end{tabular}

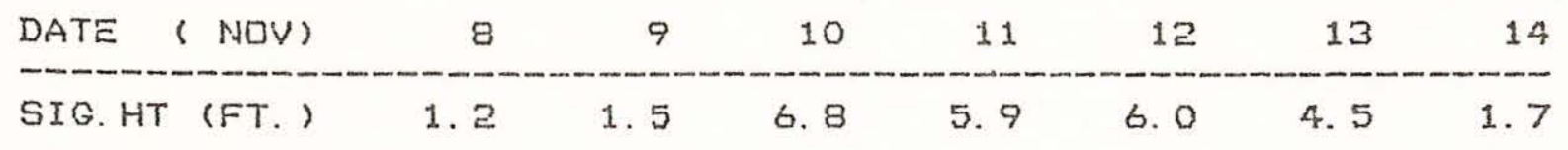

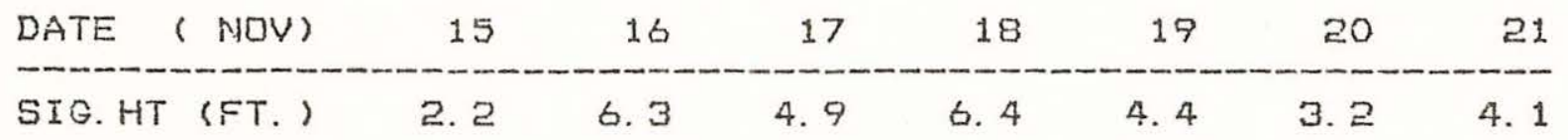

\begin{tabular}{lcccccrr} 
DATE ( NOV) & 22 & 23 & 24 & 25 & 26 & 27 & 28 \\
\hline SIG. HT (FT. ) & 4.6 & 6.5 & 6.3 & 5.7 & 5.6 & 6.1 & 4.6
\end{tabular}

\begin{tabular}{llll} 
DATE ( NOV) & 29 & 30 & 31 \\
\hline SIG. HT (FT. ) & 1.8 & 1.3 & 0.0
\end{tabular}




\section{APPENDIX III}

Summary of directional information calculated from slope array of four pressure sensors, in which the Sea Data 635-9 was embedded. Times are PDT; tinree hours must be added to convert to EDT for comparison with data from Appendix I. Angles, relative to true north, indicate direction of propagation of waves within each period band. No estimates of directional spread are given. Data provided by Dr. R.J. Seymour. 
WAVE DIRECTION IN PERIOD BANDS

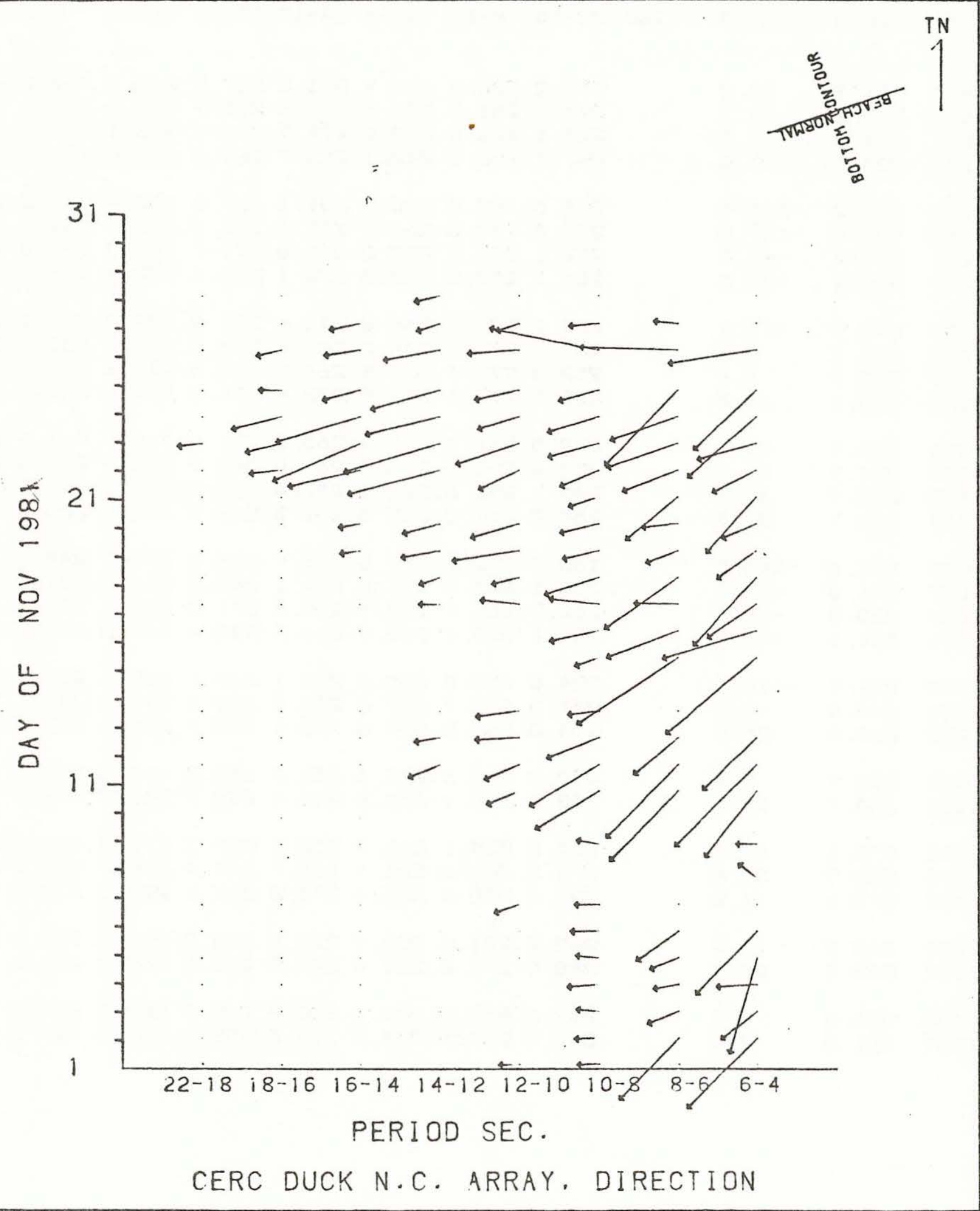


CERC DUCK N.C. ARRAY, DIRECTION NOV 1980

LDCAL SIG. ANG TOT. SXY DAY/TIME (DEG) (CM. SQ)
ANGULAR DISTRIBUTION IN PERIOD BANDS

(ANGLES IN DEGREES)

BAND PERIOD LIMITS (SECS)

$22+22-18 \quad 18-16 \quad 16-14 \quad 14-12 \quad 12-10 \quad 10-8$ 8-6 $6-4$

\begin{tabular}{|c|c|c|c|}
\hline 1 & 0437 & 266.8 & 14.0 \\
\hline 1 & 1037 & 265.1 & 11. 5 \\
\hline 1 & 1637 & 271.5 & 17.9 \\
\hline 1 & 2236 & 224.7 & -369.0 \\
\hline 2 & 0436 & 227. ᄅ & -250.5 \\
\hline 2 & 1036 & 235.6 & -147.5 \\
\hline 2 & 1639 & 235.4 & -65.3 \\
\hline$\overline{2}$ & 2243 & 238.9 & -41.8 \\
\hline & 0436 & 245.0 & -11.1 \\
\hline 3 & 1038 & 250.7 & \\
\hline 3 & 1630 & 252. 5 & 6. 1 \\
\hline 3 & 2238 & 264.6 & 41.5 \\
\hline 4 & 0436 & 265.9 & 30. \\
\hline 4 & 1038 & 264.9 & 21.2 \\
\hline 4 & 1637 & 278. 1 & 65. 1 \\
\hline 4 & 2237 & 280.7 & 87.5 \\
\hline 5 & 0436 & 225. 6 & -146 \\
\hline 5 & 1037 & 231.0 & -93.8 \\
\hline 5 & 1638 & 233. 8 & -61.1 \\
\hline 5 & 2236 & 234. 1 & -42.4 \\
\hline 6 & 0437 & 231.9 & -118 \\
\hline 6 & 1636 & 249.4 & \\
\hline 6 & 2237 & 262. 3 & 28.8 \\
\hline 7 & 0437 & 259.4 & \\
\hline 7 & 1035 & 264.7 & 20. \\
\hline 8 & 0436 & 275.1 & 14. \\
\hline 8 & 1044 & 282. 9 & \\
\hline 8 & 1639. & 273.6 & 14. \\
\hline 9 & 1039 & 268. 3 & \\
\hline & 1637 & 268.9 & \\
\hline & 0438 & 26 & \\
\hline & 1039 & 261.5 & \\
\hline
\end{tabular}

255. 2 252. 7 268. 9 271. 8 267. 8 268. 5 267. 2 253. 7 244.6 261. 5 270. 5 270. 6 275. 7 274. 0 268. 8 235. 3 254. 5 268. 0 262. 3277.7 270. 9275.1 280. 9 256. 2 247. 1 296. 5 242. 1253.7269 .6 273. 0241.4 220. 3

247. 0 258. 0 252. 6 231. 1 269.6 267. 9 224. 2 225. 2 337.4 257. 0 261. 9 272. 4 277. 6 252. 5 236. 1 229. 0 272. 1 272. 9 257. 8 296. 5271.7 264. 0 231. 8.229 .7 264. 1 258. 2 262. 8 270. 1 278. 5 272. 8 236. 6 Е3e.

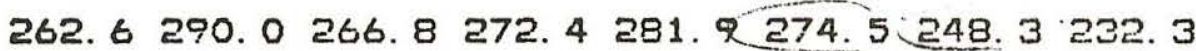
253. 8 270. 5 284. 2 263. 0 276. 9274.4255 .7235 .9 252. 3 271. 4 260. 9 264. 5 273. 5 293. 5 256. 2 237. 6 258. 4 273. 6 252. 9 273. 4 272. 8 271. 9 265. 4 260. 7

278. 5 255. 9 269. 4 265. 2 271. 9 266. 0 261. 0 267. 1 259.6 256. 6 276. 9261.0265 .9 568. 9 263. 6 262. 7 242. 1 296. 5 253. 1 255. 4 265. 2 276. 0 266. 2 284. 5 254. 2 251. 5 259. 5 258. 3 268. 3 274. 8 285. 0 282. 7

163. 5 252. 3271.8 265. 7 268: 5 275. 7 248. 7 196. 3 250. 1 265. 9 271. 5 254. 1 269. 2 266. 6 237. 5 222. 3 265. 7 260. 9 250. 9 259. 2271.0266 .7 236. 0 227. 6 260. 5 269. 5 252. 9264.1258 .4268 .3259 .6220 .9

234. 6 179. 8 260. 0 257. 1 265. 1 269. 7 235. 2 224. 5 251. 5 250. 7 257. 6 262. 0 260. 2270.4247 .3231 .3 254. 8 261. 0264.6253 .1256 .7270 .5 263. 3243.0 238. 3 255. 5 257. 4 251. 2 252. 0 258. 8 270. 1 255. 6 253. 2 266. 1 259. 249.4 258. 1268.4 277. 0 273. 9

254. 2 259. 1 263. 9 258. 2 267. 3 270. 8 277. 2 308. 5 273. 3263.8 261. 1 256. 7264.4274 .0 296. 5 286. 5 233. 5 258. 0 259. 4 274. 8 261. 1 273. 5 277. 4.315 .9

262. 2 251. 5 255. 9 257. 2 253. 3 280. 4 276. 9270.3 268. 9271.2251 .4247 .3259 .5269 .7 266. 5315.3 278. 6 250. 0249.7 250. 9 259. 3 268. 8 272. 8 258. 7 330. 8 251. 5 255. 2 252. 3 258. 1 264. 5 262. 2 255. 6 
CERC DUCK N.C. ARRAY, DIRECTION NOV 1980

$\begin{array}{llrr}\text { LDCAL } & \text { SIG. ANG } & \text { TOT. SXY } \\ \text { DAY/TIME } & \text { (DEG) } & \text { (CM. SQ) } \\ 10 & 1635 & 222.3 & -218.7 \\ 10 & 2238 & 227.8 & -726.9 \\ 11 & 0435 & 224.3 & -580.1 \\ 11 & 1037 & 229.0 & -325.8 \\ 11 & 1637 & 229.2 & -264.7 \\ 11 & 2237 & 230.9 & -410.8 \\ 12 & 0437 & 232.0 & -470.9 \\ 12 & 1039 & 230.2 & -424.8 \\ 12 & 1640 & 233.6 & -235.2 \\ 12 & 2237 & 229.6 & -346.3 \\ 13 & 0436 & 236.2 & -199.2 \\ 13 & 1042 & 240.0 & -93.5 \\ 13 & 1639 & 248.3 & -15.2 \\ 13 & 2238 & 256.8 & 28.5 \\ 14 & 1037 & 263.0 & 28.0 \\ 14 & 1643 & 262.4 & 19.4 \\ 14 & 2242 & 259.8 & 8.6 \\ 15 & 04.22 & 260.5 & 7.0 \\ 15 & 1042 & 258.6 & 5.0 \\ 15 & 1642 & 258.0 & 4.9 \\ 15 & 2242 & 230.2 & -59.5 \\ 16 & 0442 & 229.5 & -555.7 \\ 16 & 1042 & 234.3 & -305.2 \\ 16 & 1640 & 238.0 & -225.2 \\ 16 & 2239 & 238.3 & -154.6 \\ 18 & 1726 & 235.2 & -181.7 \\ 17 & 0436 & 244.0 & -68.5 \\ 17 & 1037 & 253.4 & 23.6 \\ 17 & 1643 & 255.5 & 54.7 \\ 17 & 2248 & 271.2 & 329.0 \\ & & & \\ 18 & 1043 & 235.2 & -203.5\end{array}$

\section{ANGULAR DISTRIBUTION IN PERIOD BANDS (ANGLES IN DEGREES) BAND PERIOD LIMITS (SECS)}

$22+22-18 \quad 18-16 \quad 16-14 \quad 14-12 \quad 12-10 \quad 10-8 \quad 8-6 \quad 6-4$ 265. 4 269. 5 257. $9255.5253 .5260 .4237 .5194 . ?$ 206. 5 212. 6 246. 3 258. 8 244. 3 235. 0 222. 7 224. 7 236. 9 219. 2 258. 8 240. 0 237. 7 239. 2 221. 8 220. 9 252. 9 248. 3 245. 8 249. 2 247. 8 239. 0 224. 5 218. 4 231. 1 206. 5 251. 2 246. 4 243. 1 238.8. 227. 1 218. 9 241. 1245.7 250. 1 247. 0 248. 3 242. 1 "24.8.190. 8

240. 7 227. 9 251. 5251.6 245.6 239. 8 225. 0 226. 3 243. 3261.7244 .7247 .2246 .9 238. 9 224. 8 225. 3 170.6 238. 0 248. 6 251. 4 249. 4 244. 5 229. 1 224. 206. 5 224. 4 243. 2 249. 8 249. 9 243. 0 227. 4 222. 4

241.2 250. 7 261. 4 259. 7 256. 3 249. 1 232. 1 226. 3 250. 3 254. 2 264. 2 260. 9 267. 5 248. 5 230. 7 226. 1 259. 5 267.6 244. 8 249. 3 257.6 257. 0 233. 5 23. 9 244. 0267.7 258. 9 259. 1 264. 8 253. 8 243. 9 234. 6

256. 8 259. 4 259. 3 265. 6 262. 7 263. 1 266. 1 265. 1 247. 5 259. 5 270. 2 261. 4261.5264 .3260 .6 253. 0 251. 5271.7260 .9246 .4 261. 1 264. 3264.6 269. 9

249. 1 242. 0 258. 1 263. 0 258. 7 265. 1 262. 2 252. 5 242. 5 257. 1 271.9 251.7.250.9 267. 0 268. 6 267. 3 239. 9 252. 7 260. 1 252. 4 255. 1 268. 4 265. 6 260. 9 223. 2 265. 4 271. 1 252. 1 255. 7 259. 9 234. 9 224. 4

227. 8 242. 6 264. 0 253. 8 256. 5 250. 1 228. 4 229. 4 242. 5 226. 0 255. 1 253. 4 257. 9 250. 3 236. 7230.2

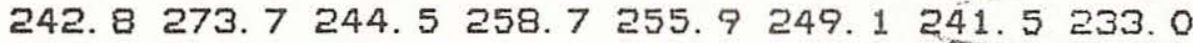
256. 6 275. 1 251. 1 270. 8 255. 4 248. 8237.7 236.

249. 9 248. 7 251. 5 262. 7 265. 1 258. 0 243. 6 237. \& 254. 0 273. 3 261. 5 266. 0 261. 3 258. 2 249. 7 253. 8 257. 0 227. 6 260. 6 254. 6 262. 4 268. 3 253. 9251.8 179. 1267.7 246. 5 261. 7 255. 0 270. 0 274. 5 26 7.6

243. 6 261. 1 276. 5 270.6 276. 6 276. 4 271.6 235.7 206. 5 253. 4 282. 0 287. 3 296. 5 274. 9 228. o 219.4 230. 4 252. 9 264. 1 251. 7 274. 0 251. 5 226. 0 222. 3 273. 3 245. 5 256. 3 251. 4 256. 1 252. 7 235. 1 223. 1 
CERC DUCK N.C. ARRAY, DIRECTION NOV 1980

\begin{tabular}{|c|c|c|c|}
\hline \multicolumn{2}{|c|}{$\begin{array}{l}\text { LOCAL } \\
\text { DAY/TIME }\end{array}$} & SIG. ANG & $\begin{array}{l}\text { TOT. SXY } \\
\text { (CM. SQ) }\end{array}$ \\
\hline 19 & 1707 & 236.3 & -106.3 \\
\hline 19 & 2304 & 239.4 & -60.9 \\
\hline 20 & 0504 & 248.7 & -13.7 \\
\hline 20 & 1040 & 253. 8 & 28. 5 \\
\hline 20 & 1640 & 250. 1 & -4.6 \\
\hline 20 & 2240 & 252.6 & 13. 0 \\
\hline 21 & 0439 & 253.6 & 13. 8 \\
\hline 21 & 1047 & 255.6 & 26.3 \\
\hline 21 & 1646 & 241.8 & -58.4 \\
\hline 21 & 2239 & 232.7 & -191.1 \\
\hline 22 & 0440 & 227.4 & -312.9 \\
\hline 22 & 1040 & 231. 8 & -137.8 \\
\hline 22 & 1640 & 231.9 & -111.2 \\
\hline 22 & 2240 & 242. 0 & -27.3 \\
\hline 23 & 0440 & 244.6 & -22.7 \\
\hline 23 & 1039 & 고. 8 & 34.4 \\
\hline 23 & 1640 & 254.9 & 139.0 \\
\hline 23 & 2236 & 256. 1 & 158.6 \\
\hline 24 & 0440 & 258. 4 & 230.4 \\
\hline 24 & 1042 & 251.7 & 3. 3 \\
\hline 24 & 1634 & 256.9 & 184.5 \\
\hline 24 & 2242 & 255.6 & 102.0 \\
\hline 25 & 1043 & 248.2 & -49.8 \\
\hline 25 & 1641 & 245.9 & -99.8 \\
\hline 25 & 2241 & 241.8 & -189.1 \\
\hline 20 & 0441 & 244.1 & -139.8 \\
\hline 26 & 1048 & 237.8 & -242.6 \\
\hline 26 & 1709 & 245.4 & -57.9 \\
\hline 27 & 2249 & 270.1 & 478.4 \\
\hline 28 & 0446 & 268.7 & 272. 1 \\
\hline 28 & 1646 & 258.6 & 35.6 \\
\hline 28 & 2243 & 259.3 & 20. 1 \\
\hline 29 & 0444 & 256. 1 & 11. 3 \\
\hline
\end{tabular}
ANGULAR DISTRIBUTION IN PERIOD BANDS (ANGLES IN DEGREES)
BAND PERIOD LIMITS (SECS)

$22+22-18 \quad 18-16 \quad 16-14 \quad 14-12 \quad 12-10$ 10-8 $8-6 \quad 6-4$

229. 2 259. 3 261. 2 253. 5 253. 1 244. 3 233. 4 226. 7 253. 1257.7 258. 4 256. 5 251. 6 249. 2 238. 7 222. 8

260. 7 255. 1 249. 1 258. 9 252. 3 255. 6 241. 4 229. 5 262. 1249.7261 .7259 .8261 .6 256. 5 248. 9234.6 273. 0 259. 8 252. 2 249. 1 257. 9 251. 7 248. 6 236. 5 "296. 5 254. 1260.9250 .3252 .8 257. 0257.3239 .8

255. 7 254. 2 258. 7 253. 3 252. 3 253. 2 256. 0 254. 0 259. 5 264. 2 261. 0 255. 3 254. 2 256. 8 264. 3 246. 7 258. 6 251. 8 258. 2 257. 7 256. 9 267. 3 261.6 221. 4 249. 5 253. 2 252. 6 252. 2 255. 5 253. 7 248. 0 221.6

245. 4 248. 9 252. 5 247. 3 252. 9 244. 5 226. 4 217. 6 247.4 252. 4 261. 2 260. 0 255. 1 251.6 231.0 222. 1 248. 7 262. 9 260. 0 258. 7 260. 9 252. 9 228. 7 222. 3 266. 3 260. 1 264. 2 254. 1 263. 0 257. 4 241.9 225. 2

245. 4 263. 5 253. 8 246. 6 256. 8 253. 8 245. 9231.7 261.4264 .4257 .6 255. 5244.7 247. 2 249. 2 243. 1 264. 4 262. 2 254. 2 260. 1 248. 1 248. 1 256. 2 246. 6 247. 2 255. 3 258. 4 261. 0 252. 9 252. 8 257. 3 253. 9

267.8 268. 9 262. 8 259. 3 257. 5 256. 7 254. 0 255. 9 263.6 256. $4247.1253 .5251 .8254 .9251 .5 \quad 254.7$ 263. 0 265. 7 252. 3 251. 2 254. 1 252. 9 265. 1 267. 9 265. 1 260. 2 253. 4 249. 2 251. 8267.2 262. 9 266. 0

258. 8 256. 2 253. 6 256. 6 253. 4 253. 2 250. 9 228. 7 257.6 268. 0 254. 8 252. 2 256. 2 261. 8 243. 2 227. 0 237.6261 .6 265. 2 255. 4 248. 7 256. 9 232. 1 222. 4

271. 5 265. 7 258. 8 255. 6 252. 0 253. 6 237. 7 226. 4 257. 1 271. 5 255. 3 254. 6 257. 9 254. 7 224. 2 226. 4 257.2 254. 8 250.9 253. 9 260. 2 256. 4 237. 4 229. 2

266.6257 .6261 .8260 .1266 .4281 .7272 .0261 .7 329. 9 256. 2 253. 6 251.3 263. 1 278. 0 274. 8 262. 4 238. 0 258. 3 249. 8 249. 8 261. 9267.7 265. 2 262. 1 254. 2 249. 3 258. 7 251. 4 251. 8 265. 1 275. 4 258. 0

250.0253 .6246 .7254 .0259 .2271 .3270 .7260 .8 


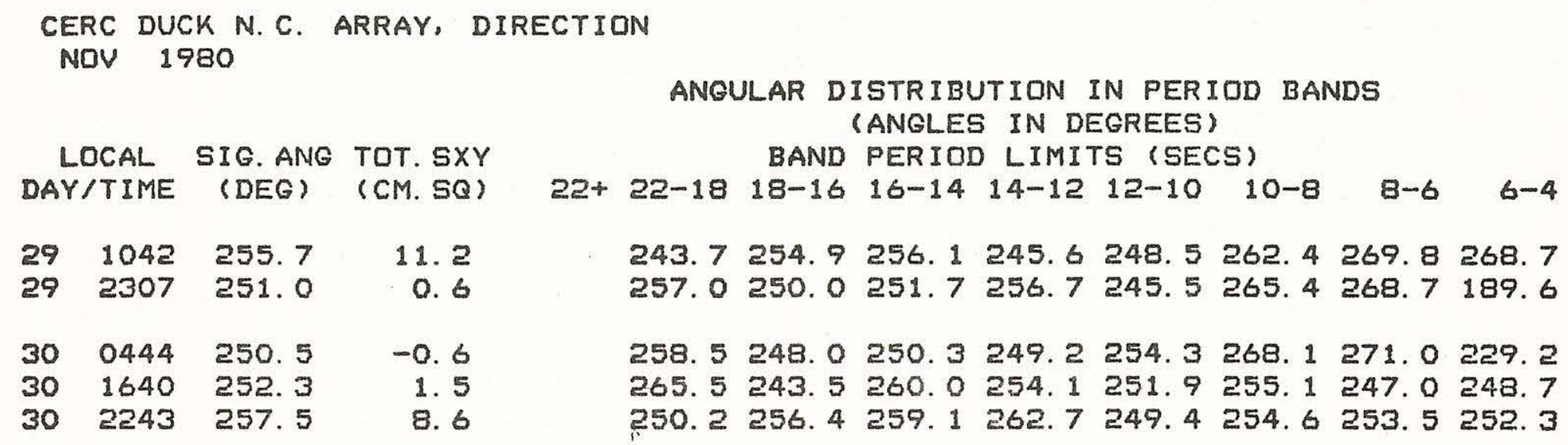


May 1980

DISTRIBUTION FOR SEA GRANT REPORTS

No. of Copies

3

5

25

1

\section{Address}

National Sea Grant Depository

Pell Marine Science Library

University of Rhode Island

Kingston, RI 02881

Office of Sea Grant

6010 Executive B1vd.

Rockville, MD 20852

NOAA

Library \& Information Serv. Div. OA/D825

6009 Executive Blvd.

Rockville, MD 20852

Sea Grant Today

Editor, Food Science and Technology VPI \& SU

Blacksburg, VA 24061 


\begin{tabular}{|c|c|c|}
\hline $\begin{array}{l}\text { REPORT DOCUMENTATION } \\
\text { PAGE }\end{array}$ & 1. REPORT NO. WHOI $-81-28$ & 3. Recipient's Accession No. \\
\hline \multirow{2}{*}{\multicolumn{2}{|c|}{$\begin{array}{l}\text { 4. Title and Subtitle } \\
\text { FIELD EVALUATION OF SEA DATA DIRECTIONAL WAVE GAGE } \\
\text { (MODEL 635-9) }\end{array}$}} & $\begin{array}{l}\text { 5. Report Date } \\
\text { May } 1981 \\
\end{array}$ \\
\hline & & 6. \\
\hline \multicolumn{2}{|l|}{$\begin{array}{l}\text { 7. Author(s) } \\
\text { D. G. Aubrey }\end{array}$} & 8. Performing Organization Rept. No. \\
\hline \multirow{2}{*}{\multicolumn{2}{|c|}{$\begin{array}{l}\text { 9. Porforming Organization Name and Address } \\
\text { Woods Hole Oceanographic Institution } \\
\text { Woods Hole, Massachusetts } 02543\end{array}$}} & 10. Project/Task/Work Unit No. \\
\hline & & $\begin{array}{l}\text { 11. Contract(C) or Grant(G) No. } \\
\text { (C) NA79AA-D-00102 } \\
\text { (G) NA80AA-D-00077 } \\
\text { DAAG29-81-K-004 }\end{array}$ \\
\hline \multirow{2}{*}{\multicolumn{2}{|c|}{$\begin{array}{l}\text { 12. Sponsoring Organization Name and Address } \\
\text { Department of Commerce, NOAA, Office of Sea Grant } \\
\text { U.S. Army Research Office }\end{array}$}} & $\begin{array}{l}\text { 13. Type of Report \& Period Covered } \\
\text { Technical }\end{array}$ \\
\hline & & \\
\hline
\end{tabular}

15. Supplementary Notes

16. Abstract (Limit: 200 words)

A directional wave gage consisting of a two-axis electromagnetic current meter and pressure sensor, developed by Sea Data Corporation, with modifications specified by the author, was successfully deployed during the joint NOAA/U.S. Army Corps of Engineers Coastal Engineering Research Center's Atlantic Remote Sensing Land/Ocean Experiment (ARSLOE) during November, 1980. Data recovery rate was $100 \%$, and instrument function was verified through comparison with a four-element presuure sensor array at the same location, and $x$-band imaging radar, and with surface meteorological observations charting developing local wave fields. The instrument was proven to be a viable alternative for point measurements of directional wave fields and for estimating the first five fourier coefficients in a directional wave model.

17. Document Analysis a. Descriptors

1. Directional wave spectra

2. Wave measurement instrumentation

3. ARSLOE

b. Identifiers/Open-Ended Terms

19. Security Class (This Report) 20. Security Class (This Page)
21. No. of Pages

52

22. Price 


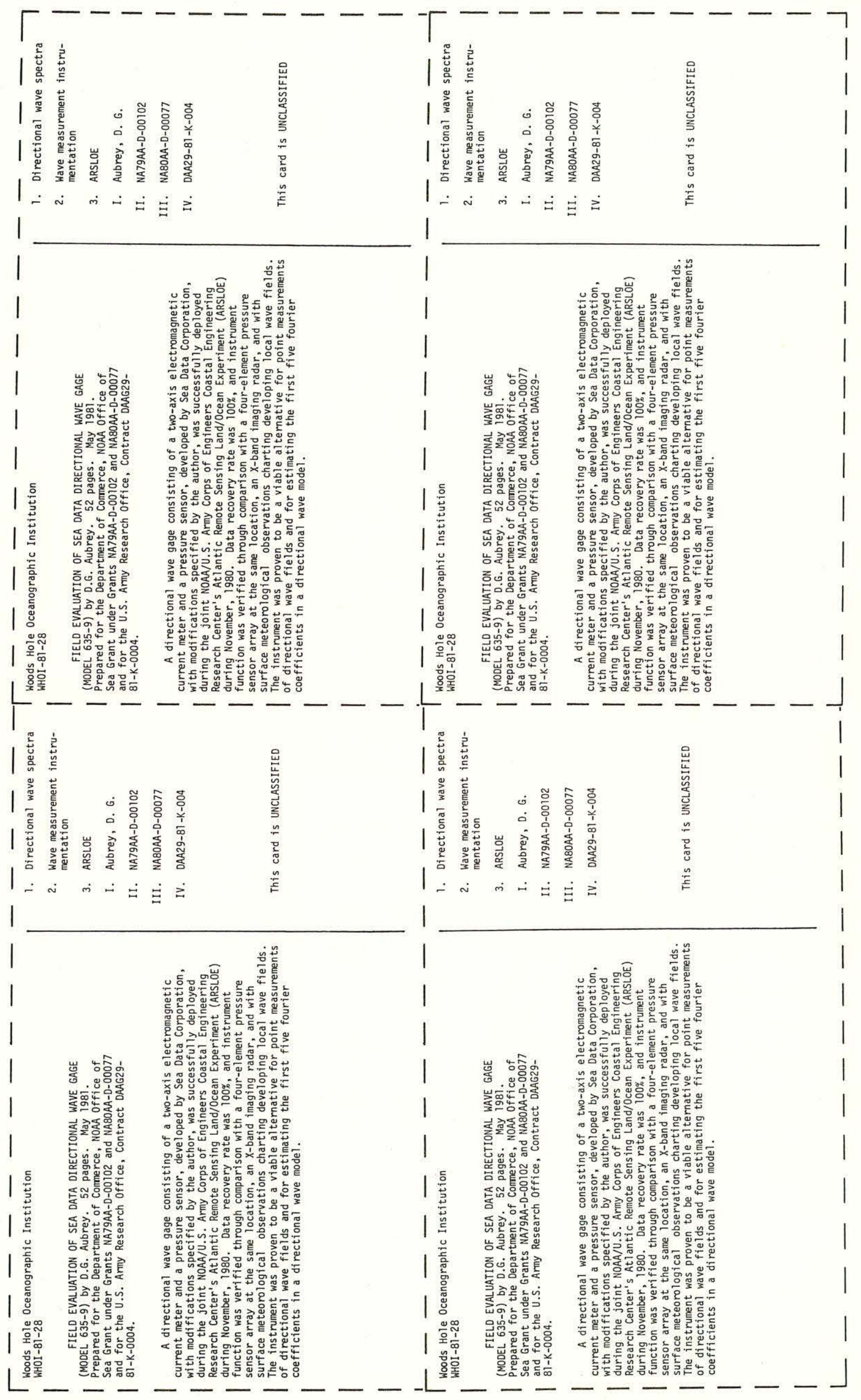

